OPEN ACCESS

Edited by:

Linda F. Van Dyk

University of Colorado Denver,

United States

Reviewed by:

Arshad Khan

McGovern Medical School at

UTHealth, United States

Eva Kaufmann,

McGill University Health

Centre, Canada

*Correspondence:

Antje Blumentha

a.blumenthal@uq.edu.au

${ }^{\dagger}$ Present address:

Thao Thanh Tran,

Biology Department, School of

Education, Can Tho University,

Can Tho, Vietnam

Specialty section:

This article was submitted to

Microbial Immunology,

a section of the journal

Frontiers in Immunology

Received: 01 July 2019

Accepted: 10 October 2019

Published: 08 November 2019

Citation:

Ljungberg JK, Kling JC, Tran TT and

Blumenthal A (2019) Functions of the

WNT Signaling Network in Shaping

Host Responses to Infection.

Front. Immunol. 10:2521.

doi: 10.3389/fimmu.2019.02521

\section{Functions of the WNT Signaling Network in Shaping Host Responses to Infection}

\author{
Johanna K. Ljungberg, Jessica C. Kling, Thao Thanh $\operatorname{Tran}^{\dagger}$ and Antje Blumenthal* \\ The University of Queensland Diamantina Institute, The University of Queensland, Brisbane, QLD, Australia
}

It is well-established that aberrant WNT expression and signaling is associated with developmental defects, malignant transformation and carcinogenesis. More recently, WNT ligands have emerged as integral components of host responses to infection but their functions in the context of immune responses are incompletely understood. Roles in the modulation of inflammatory cytokine production, host cell intrinsic innate defense mechanisms, as well as the bridging of innate and adaptive immunity have been described. To what degree WNT responses are defined by the nature of the invading pathogen or are specific for subsets of host cells is currently not well-understood. Here we provide an overview of WNT responses during infection with phylogenetically diverse pathogens and highlight functions of WNT ligands in the host defense against infection. Detailed understanding of how the WNT network orchestrates immune cell functions will not only improve our understanding of the fundamental principles underlying complex immune response, but also help identify therapeutic opportunities or potential risks associated with the pharmacological targeting of the WNT network, as currently pursued for novel therapeutics in cancer and bone disorders.

\section{Keywords: WNT signaling, antigen presenting cells (APCS), infection, inflammation, anti-microbial defense}

\section{THE WNT SIGNALING NETWORK}

The WNT signaling network is a central regulator of embryonic development and tissue homeostasis. WNT proteins are phylogenetically highly conserved secreted, cysteine-rich glycolipoproteins (1). Nineteen individual WNT proteins have thus far been described in mammals (2). Best known functions of WNT proteins include regulation of cell cycle, cellular differentiation, cell motility, cellular polarity, and cell death (3). WNT proteins act as directional growth factors that orchestrate patterning, expansion and differentiation of tissues in the organized formation of body plans, and are central regulators of stem and progenitor cell development and maintenance both during embryogenesis and adult homeostasis $(4,5)$. Dysregulation of WNT signaling is implicated in a multitude of diseases, including cancer, fibrosis, bone density disorders, metabolic and neurodegenerative diseases (6).

WNT proteins are highly hydrophobic due to post-translational modification by palmitoleic and palmitic acid at conserved cysteine residues. This is afforded through action of the acyltransferase Porcupine (PORCN) in the endoplasmic reticulum (Figure 1). WNT acylation has been shown to be required for the release, receptor interactions, and functions of WNTs (1). The chaperone Wntless (WLS) facilitates transport of acylated WNT ligands to the plasma membrane and aids in 


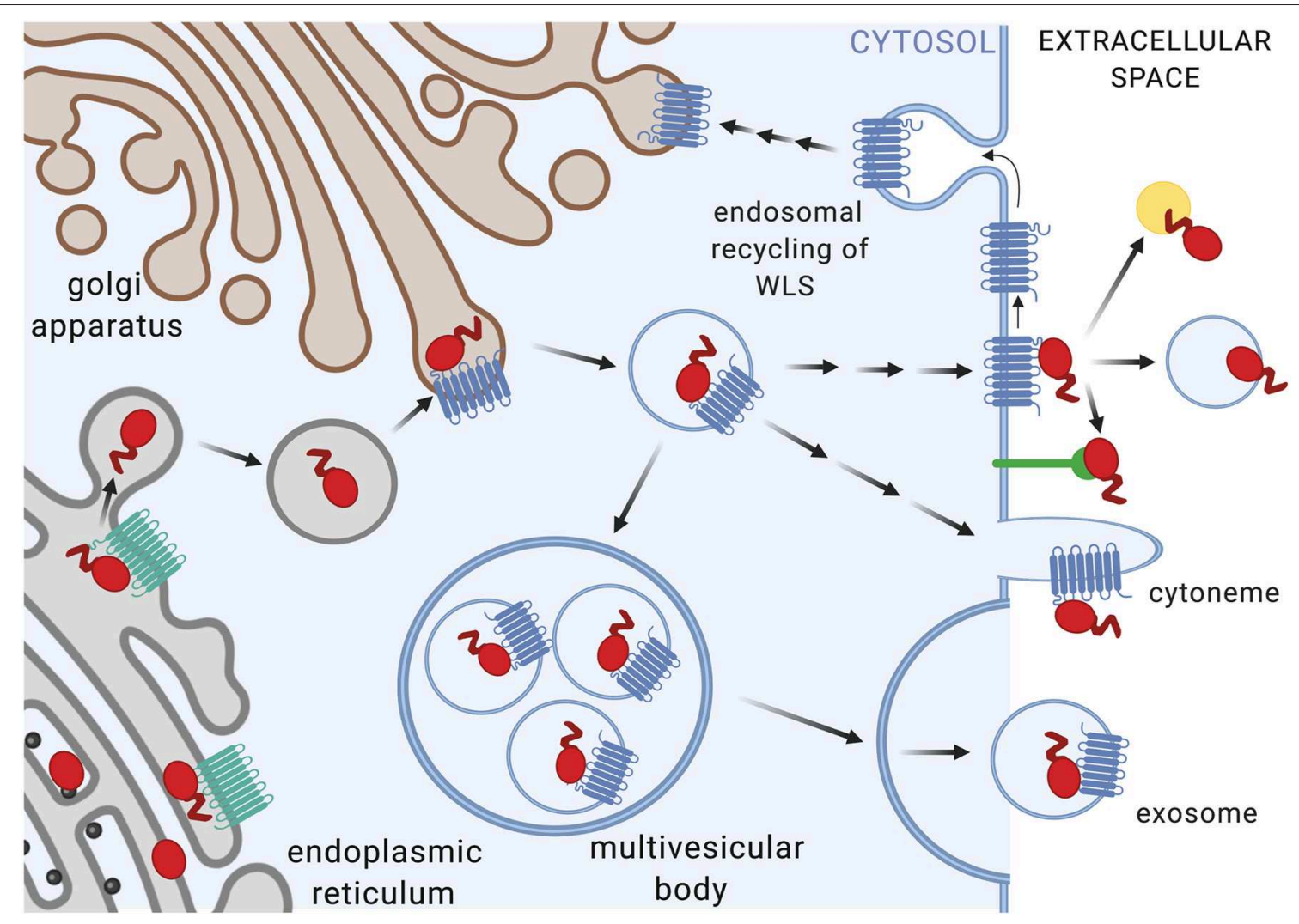

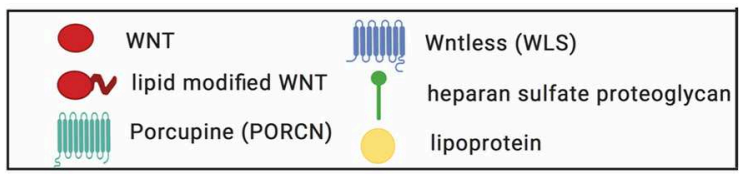

FIGURE 1 | Posttranslational modification and secretion of WNT ligands. Upon translation, WNT proteins undergo acylation in the endoplasmic reticulum by Porcupine (PORCN), a modification required for WNT release (7), receptor interactions (8), and functions (7, 9). Wntless (WLS) facilitates transport of acylated WNT ligands to the plasma membrane and aids in WNT release (10-12). WNT secretion and extracellular transport appears to occur via multiple mechanisms including multi-vesicular bodies and exosomes, cytonemes, lipoproteins, and heparan sulfate proteoglycans (1). WLS protein is recycled via clathrin-mediated endocytosis (13). Figure created with Biorender.com.

WNT release (14). WNT proteins act as morphogens in a concentration-dependent manner through the formation of gradients within tissues. How the hydrophobic WNT ligands act at short distances as well as at longer ranges is incompletely understood. Multiple mechanisms that facilitate WNT transport beyond the boundaries of the producing cell have been described, including chaperones, lipoproteins, exosomes, and cytonemes (1). Macrophages infected by viruses or intracellular bacterial pathogens release exosomes and microvesicles that contain pathogen-derived components alongside host membrane proteins (e.g., MHC-I, MHC-II) and immune mediators (e.g., cytokines) that modulate functions of bystander cells (15-18). Observations of elevated WNT5A protein levels in serum of patients with severe sepsis (19) highlights the possibility that WNT proteins produced in response to infection may act not only locally but also systemically, and thereby shape immune cell differentiation and functions at distant sites.
WNT ligands initiate intracellular signaling by binding to cell surface-expressed WNT receptors and co-receptors, including Frizzled (FZD) 7-transmembrane domain receptors, low-density lipoprotein-related proteins (LRP5, LRP6), as well as receptor tyrosine kinases ROR and RYK (20). Cytoplasmic scaffolding proteins of the disheveled family (DVL) are central to initiating intracellular signaling downstream of FZD receptors (21). The functional outcome of WNT interactions with target cells is decided at the level of receptor engagement. Depending on the receptor context, WNT ligands activate distinct intracellular pathways, which can be grouped into $\beta$-catenin-dependent and $\beta$-catenin-independent signaling events (Figure 2). Individual modalities of $\beta$-catenin-dependent and $\beta$-catenin-independent WNT signaling have been reviewed in detail elsewhere $(3,5$, 20). Briefly, $\beta$-catenin-dependent WNT signaling is mediated by cytoplasmic stabilization of $\beta$-catenin, which is controlled by the $\beta$-catenin destruction complex. The destruction complex 


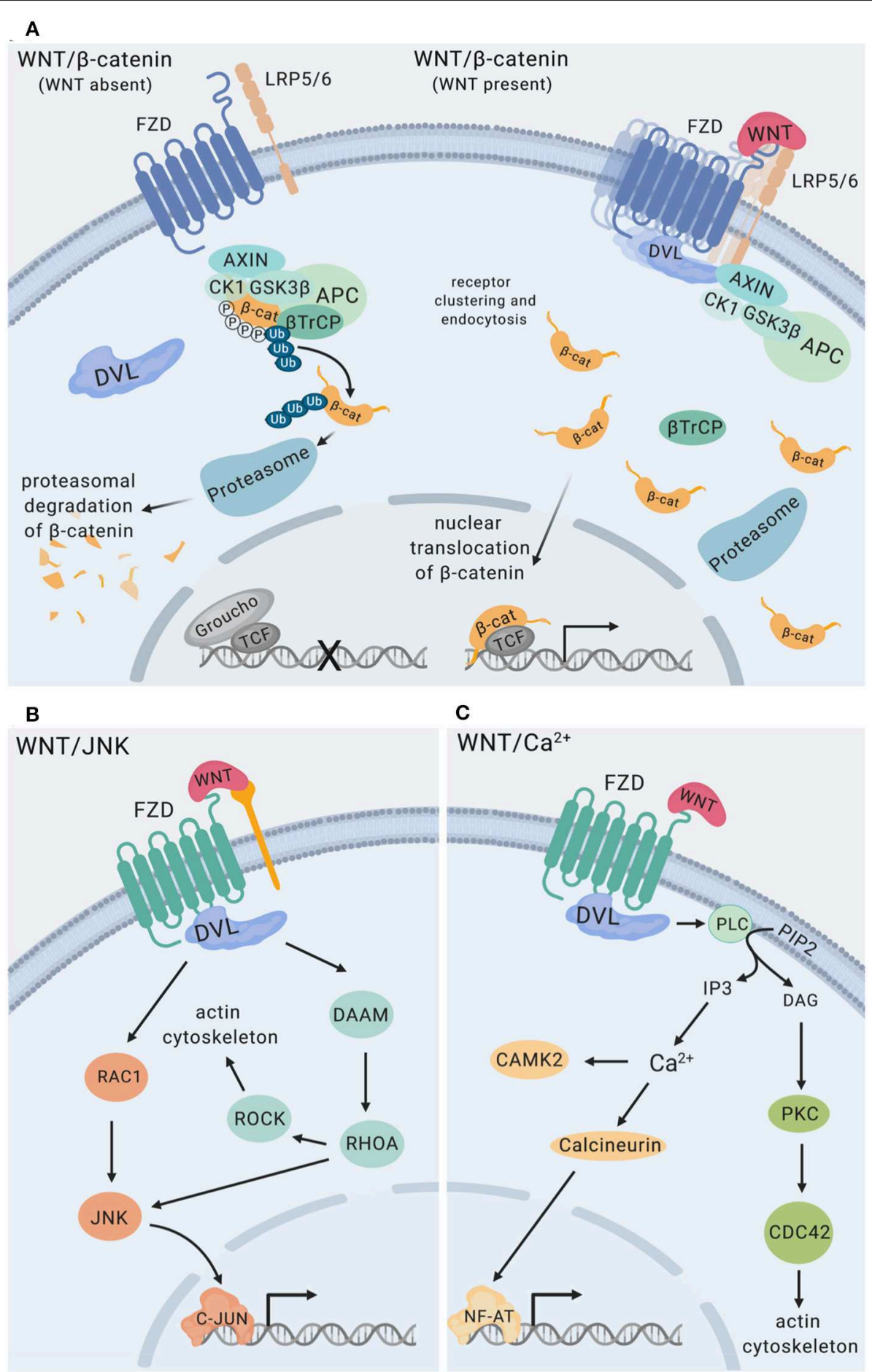

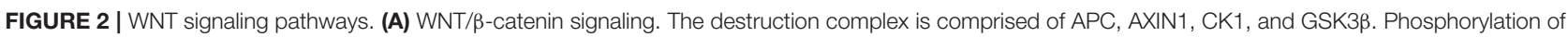
$\beta$-catenin by CK1 and GSK3 $\beta$ within the destruction complex results in $\beta$-catenin ubiquitination mediated by $\beta$-TrCP resulting in proteasomal degradation of $\beta$-catenin $(22,23)$ The transcriptional repressor Groucho suppresses expression of genes controlled by TCF/LEF transcription factors. Binding of WNT ligands to Frizzled (FZD) receptors and LRP co-receptors promotes recruitment and clustering of DVL, forming signalosomes (21, 24), facilitating recruitment of the destruction complex and stabilization of cytoplasmic $\beta$-catenin. Nuclear translocation of $\beta$-catenin enables its functions as a transcriptional co-activator for transcription factors of the TCF/LEF family (3). (B) WNT/JNK signaling via FZD, alone or in conjunction with co-receptors (e.g., ROR RYK) activates the small GTPases RAC1 and RHOA engaging the actin cytoskeleton, as well as JNK MAP kinase activation (25-27). (C) WNT/Ca ${ }^{2+}$ signaling downstream of FZD receptors is mediated by phospholipase C (PLC) activation leading to enhanced levels of cytosolic $\mathrm{Ca}^{2+}$, resulting in calmodulin/calmodulin-dependent kinase II activation and NF-AT-regulated transcriptional responses (28), and engagement of the actin cytoskeleton. RYK has been implicated as a co-receptor for WNT/ $\mathrm{Ca}^{2+}$ signaling. Figure created with Biorender.com. 
is comprised of scaffolding proteins adenomatous polyposis coli (APC), axis inhibition protein (Axin), and the kinases casein kinase 1 (CK1) and glycogen synthase kinase $3 \beta$ (GSK3 $\beta$ ). In the absence of WNT ligand binding to FZD and LRP co-receptors, phosphorylation of $\beta$-catenin by CK1 and GSK3 $\beta$ within the destruction complex results in $\beta$ catenin ubiquitination by beta-transducin repeat-containing E3 ubiquitin protein ligase ( $\beta \operatorname{TrCP})$, fueling continuous degradation of $\beta$-catenin by the proteasome (Figure 2A). Binding of WNT ligands to FZD/LRP results in recruitment of DVL and the destruction complex, inhibiting GSK3 $\beta$ and CK1 activity and stabilization of cytoplasmic $\beta$-catenin. This enables nuclear translocation of $\beta$-catenin where it functions as transcriptional co-activator for transcription factors of the TCF/LEF family (Figure 2A). WNT/JNK- [described as planar cell polarity (PCP) pathway in Drosophila] and WNT/Ca ${ }^{2+}$-signaling are modes of $\beta$-catenin-independent WNT signaling. WNT/JNK signaling results in FZD/DVL-mediated activation of the small GTPases RAC1 and RHOA, directing cytoskeletal rearrangements, cell polarization and motility. Activation of JNK can drive c-Jun- and AP-1-controlled transcription (Figure 2B). WNT/Ca ${ }^{2+}$ signaling downstream of FZD receptors and DVL leads to phospholipase $\mathrm{C}$ (PLC) activation and enhanced levels of cytosolic $\mathrm{Ca}^{2+}$, which activates calmodulin/calmodulin-dependent kinase II and NFATregulated transcriptional responses (Figure $2 \mathrm{C}$ ).

Tight regulation and precise targeting of WNT signaling is essential, as emphasized by the evolutionary investment in multiple layers and modes of WNT pathway modulation. WNT signaling is negatively regulated by secreted Frizzledrelated proteins (sFRP) and WNT inhibitory factor 1 (WIF-1), which directly bind WNT proteins interfering with receptor interactions (3). The palmitoleoyl-protein carboxylesterase Notum was shown to facilitate serine de-palmitoleoylation of WNT ligands, thereby negatively regulating WNT functions (29). Members of the Dickkopf (DKK) and Sclerostin/SOST families, as well as the glycoprotein Dorsal Inhibitory Axon Guidance Protein (DRAXIN) interact with LRP5/6 and interfere with WNT binding (30-32). FZD receptor surface availability is regulated through the E3 ubiquitin ligases, Zinc and Ring Finger 3 (ZNRF3) and Ring Finger protein 43 (RFN43), which ubiquitinate FZD receptors destining them for proteasomal degradation (33). ZNFR3 and RFN43 serve as negative feedback regulators for WNT signaling, as they themselves are encoded by WNT target genes (5).

\section{WNT RESPONSES TO INFECTION}

Early studies identified $W N T 5 A$ as a highly responsive gene in human macrophages upon microbial encounter $(19,34)$. WNT5A has also been found to be highly expressed by tumor-associated macrophages (35), synoviocytes in rheumatoid arthritis (36), macrophages in atherosclerotic plaques (37), and adipose tissueresident macrophages in obesity (38). This has directed initial attention toward elucidating immune functions of WNT5A. However, it is increasingly evident that the host response to infection encompasses differential expression of multiple
WNT ligands, receptors and regulators (39-43). Thus, detailed understanding of how the concerted actions of WNT ligands and potentially concurrent WNT signaling events define host responses to infection is key to firmly establishing immune functions of the WNT signaling network.

\section{Bacterial Infections Gram-Negative Bacteria}

WNT responses to infection have been studies in the context of experimental infection with a limited number of Gram-negative bacterial pathogens (Table 1). WNT pathway activation and functions in the context of Salmonella infection have largely been focused on in a model of gastroenteritis in antibiotic-pretreated mice, as well as in epithelial cell lines in vitro. Salmonella (S.) enterica serovar Typhimurium infection of streptomycinpretreated mice increased mRNA expression of Wnt3, Wnt6, $W n t 9 a$, and protein expression of Wnt 2 and Wnt11 in intestinal tissues $(43,50,56)$. In vitro studies indicated that colonization of murine intestinal epithelial cells with $S$. Typhimurium induced elevated mRNA expression of Wnt2 and Wnt11 (also confirmed at protein level), Fzd2, Fzd4, Fzd6, Fzd7, Fzd8, Fzd9, with limited or no effects on the expression of other Wnt and Fzd genes (50, 56). Induction of Wnt 2 and Wnt11 expression was attributed at least in part to Salmonella AvrA $(50,56)$, a bacterial effector that has been implicated in the regulation of $\beta$-catenin ubiquitination and stabilization (64-67). With an increasing understanding of the complex WNT response in Salmonella infection, future studies should explore WNT network activation in macrophages, innate immune cells that are important in the host control of Salmonella infection. Thus far, it has been noted that $W n t 5 a$ and Fzd4 expression in S. Typhimurium-infected murine peritoneal macrophages was modestly increased, albeit the impact on the expression of other WNT signaling components was not explored in this study (44).

Ehrlichia (E.) chaffeensis infection of human THP-1 macrophage-like cells transiently increased mRNA expression of WNT6, WNT10A, FZD5, and FZD9, while decreasing expression of $W N T 5 B, W N T 7 B$, and FZD7, as determined by pathwayspecific qPCR arrays (42). Expression of WNT regulators such as $D K K 3$ and $s F R P 2$ was suppressed or enhanced, respectively, and a significant number of WNT-target genes were differentially expressed (42).

WNT responses upon encounter of pathogenic and nonpathogenic Escherichia (E.) coli have been investigated to some extent in mouse models in vivo. Mono-colonization of mice with E. coli F18 enhanced expression of Wnt2 in the intestine compared to germ-free mice (50). Bladder infection with uropathogenic E. coli (UPEC) induced rapid downregulation of Wnt5a expression in the urothelium of infected mice, which was partially attributed to the bacterial virulence and adhesion factor, FimH (58). This observation seems to contrast a small increase of WNT5A expression described in a human urothelial cell line infected with UPEC in vitro (59). Yet, exposure of mouse thioglycolate-elicited peritoneal macrophages exhibited a marked decrease in $W n t 5 a$ mRNA expression when exposed to a non-pathogenic E. coli strain, while expression of all other WNT ligands remained unaltered at the time point 
TABLE 1 | Bacteria-induced WNT responses in experimental systems and patient samples.

\begin{tabular}{|c|c|c|c|c|c|c|c|c|}
\hline & Mycobacterium sp. & S. aureus & S. pneumoniae & E. chaffeensis & E. coli & P. aeruginosa & S. Typhimurium & LPS \\
\hline WNT1 & $\begin{array}{l}\uparrow \text { mRNA Mtb murine } \\
\text { lung tissue }(40) \\
\text { unaffected } \mathrm{mRNA} \\
\text { M. bovis BCG } \\
\mathrm{mPM}(44)\end{array}$ & $\begin{array}{l}\downarrow \text { mRNA } \\
\text { mom-2 C. elegans IEC } \\
\text { (45) } \\
\text { unaffected mRNA } \\
\text { mPM (44) } \\
\text { unaffected L. vannamei } \\
\text { HP, LO, HT (46) }\end{array}$ & - & n.d. mRNA THP-1 (42) & $\begin{array}{l}\text { unaffected mRNA } \\
\text { mPM (44) }\end{array}$ & - & $\downarrow$ protein HCT116 (47) & $\begin{array}{l}\uparrow \text { protein THP- } 1 \text { (48) } \\
\uparrow \text { mRNA mBMDM (40) } \\
\downarrow \text { mRNA fetal ovine lungs } \\
\text { (49) } \\
\text { n.d. mRNA murine } \\
\text { spleen (39) }\end{array}$ \\
\hline WNT2 & $\begin{array}{l}\downarrow \text { mRNA Mtb murine } \\
\text { lung tissue (40) } \\
\text { unaffected mRNA } \\
\text { M. bovis BCG } \\
\text { mPM (44) }\end{array}$ & $\begin{array}{l}\uparrow \text { mRNA } \\
\text { cwn-2 C. elegans IEC } \\
\text { (45) } \\
\text { unaffected mRNA } \\
\text { mPM (44) } \\
\text { unaffected L. vannamei } \\
\text { HP, LO, HT (46) }\end{array}$ & - & n.d. mRNA THP-1 (42) & $\begin{array}{l}\uparrow \text { mRNA and protein } \\
\text { CMT93 (50) } \\
\text { unaffected mRNA } \\
\text { mPM (44) }\end{array}$ & - & $\begin{array}{l}\uparrow \text { mRNA and protein } \\
\text { IEC-18 (50) }\end{array}$ & $\begin{array}{l}\text { n.d. mRNA murine spleen } \\
\text { (39) } \\
\downarrow \text { mRNA fetal ovine } \\
\text { lungs (49) }\end{array}$ \\
\hline WNT2B & $\begin{array}{l}\downarrow \text { mRNA Mtb murine } \\
\text { lung tissue (40) } \\
\text { unaffected mRNA } \\
\text { M. bovis BCG } \\
\text { mPM (44) }\end{array}$ & $\begin{array}{l}\text { unaffected mRNA } \\
\text { mPM (44) }\end{array}$ & $\begin{array}{l}\downarrow \text { mRNA murine } \\
\text { S. pneumoniae } \\
\Delta \text { pep27 lung tissue } \\
\text { (51) }\end{array}$ & $\begin{array}{l}\text { unaffected mRNA } \\
\text { THP-1 (42) }\end{array}$ & $\begin{array}{l}\text { unaffected mRNA } \\
\text { mPM (44) }\end{array}$ & - & $\begin{array}{l}\text { unaffected mRNA } \\
\text { IEC-18 (50) }\end{array}$ & $\begin{array}{l}\uparrow \text { mRNA mBMDM (40) } \\
\text { n.d. mRNA murine } \\
\text { spleen (39) }\end{array}$ \\
\hline WNT3 & $\begin{array}{l}\text { unaffected mRNA Mtb } \\
\text { murine lung tissue (40) }\end{array}$ & - & $\begin{array}{l}\downarrow \text { mRNA murine } \\
\text { S. pneumoniae } \\
\Delta \text { pep27 lung tissue } \\
(51)\end{array}$ & $\begin{array}{l}\text { unaffected mRNA } \\
\text { THP-1 (42) }\end{array}$ & $\begin{array}{l}\text { unaffected mRNA } \\
\text { mPM (44) }\end{array}$ & - & $\uparrow$ mRNA mIEC (43) & $\begin{array}{l}\uparrow \text { mRNA hMDM (52) } \\
\text { unaffected mRNA murine } \\
\text { spleen (39) }\end{array}$ \\
\hline WNT3A & $\begin{array}{l}\downarrow \text { mRNA Mtb murine } \\
\text { lung tissue }(40) \\
\text { unaffected mRNA } \\
\text { M. bovis BCG } \\
\text { mPM (44) }\end{array}$ & $\begin{array}{l}\text { unaffected mRNA } \\
\text { mPM (44) }\end{array}$ & - & n.d. mRNA THP-1 (42) & $\begin{array}{l}\text { unaffected mRNA } \\
\text { mPM (44) }\end{array}$ & - & $\begin{array}{l}\text { unaffected mRNA } \\
\text { IEC-18 (50) }\end{array}$ & $\begin{array}{l}\text { n.d. mRNA mBMDM (40) } \uparrow \\
\text { mRNA BEAS-2B (53) } \\
\text { n.d. mRNA murine } \\
\text { spleen (39) }\end{array}$ \\
\hline WNT4 & $\begin{array}{l}\downarrow \text { mRNA Mtb murine } \\
\text { lung tissue (40) } \\
\downarrow \text { mRNA M. marinum } \\
\text { infected zebrafish (54) } \\
\text { unaffected mRNA } \\
\text { M. bovis BCG } \\
\text { mPM (44) }\end{array}$ & $\begin{array}{l}\uparrow \text { mRNA } D \text {. } \\
\text { melanogaster (55) } \\
\text { unaffected mRNA } \\
\text { mPM (44) } \\
\text { unaffected L. vannamei } \\
\text { HP, LO, HT (46) }\end{array}$ & $\begin{array}{l}\uparrow \text { mRNA murine } \\
\text { S. pneumoniae } \\
\Delta \text { pep27 lung tissue } \\
\text { (51) }\end{array}$ & $\begin{array}{l}\text { unaffected mRNA } \\
\text { THP-1 (42) }\end{array}$ & $\begin{array}{l}\text { unaffected mRNA } \\
\text { mPM (44) }\end{array}$ & - & $\begin{array}{l}\text { unaffected mRNA } \\
\text { IEC-18 (56) }\end{array}$ & $\begin{array}{l}\downarrow \text { mRNA fetal ovine lungs } \\
\text { (49) } \\
\text { unaffected mRNA murine } \\
\text { spleen (39) }\end{array}$ \\
\hline WNT5A & $\begin{array}{l}\uparrow \text { mRNA Mtb hMDM } \\
(34) \downarrow \text { mRNA Mtb } \\
\text { murine lung tissue (40) } \\
\uparrow \text { mRNA Mtb hPBMC } \\
\text { and } M \text {. bovis (BCG) } \\
\text { mPM (44) } \uparrow \text { mRNA } \\
\text { M. marinum zebrafish } \\
\text { (54) } \\
\text { WNT5A expressing } \\
\text { macrophages in human } \\
\text { tuberculosis } \\
\text { granulomas (34) }\end{array}$ & $\begin{array}{l}\uparrow \text { mRNA mPM (44) } \uparrow \\
\text { mRNA (LvWnt5) } \\
\text { L. vannamei HP, LO, } \\
\text { HT (46) }\end{array}$ & $\begin{array}{l}\downarrow \text { protein RAW264.7 } \\
\text { (57) }\end{array}$ & n.d. mRNA THP-1 (42) & $\begin{array}{l}\downarrow \text { mRNA mPM (44) } \\
\downarrow \text { mRNA murine } \\
\text { urothelium (58) } \\
\uparrow \text { mRNA human } \\
\text { urothelium (59) }\end{array}$ & $\begin{array}{l}\downarrow \text { protein } \\
\text { RAW264.7 (57) }\end{array}$ & $\begin{array}{l}\uparrow \text { mRNA mPM (44) } \\
\text { unaffected mRNA } \\
\text { IEC-18 (56) }\end{array}$ & $\begin{array}{l}\uparrow \text { mRNA hMDM (34) } \\
\uparrow \text { mRNA BEAS-2B (53) } \\
\uparrow \text { mRNA hPBMC and } \\
\text { hBMDM during sepsis (19) } \\
\uparrow \text { mRNA THP-1 (60) } \uparrow \\
\text { mRNA primary human } \\
\text { monocytes (61) } \\
\uparrow \text { mRNA RAW264.7 (37) } \\
\text { unaffected mRNA murine } \\
\text { spleen (39) } \\
\text { unaffected mBMDM (40) }\end{array}$ \\
\hline
\end{tabular}




\begin{tabular}{|c|c|c|c|c|c|c|c|c|}
\hline & Mycobacterium sp. & S. aureus & S. pneumoniae & E. chaffeensis & E. coli & P. aeruginosa & S. Typhimurium & LPS \\
\hline WNT5B & $\begin{array}{l}\downarrow \text { mRNA Mtb murine } \\
\text { lung tissue (40) } \\
\text { unaffected mRNA } \\
\text { M. bovis BCG } \\
\text { mPM (44) }\end{array}$ & $\begin{array}{l}\text { unaffected mRNA } \\
\text { mPM (44) } \\
\uparrow \text { mRNA (LvWnt5) } \\
\text { L. vannamei HP, LO, } \\
\text { HT (46) }\end{array}$ & $\begin{array}{l}\uparrow \text { mRNA murine } \\
\text { S. pneumoniae } \\
\Delta \text { pep27 lung tissue } \\
\text { (51) }\end{array}$ & $\downarrow$ mRNA THP- 1 (42) & $\begin{array}{l}\text { unaffected mRNA } \\
\text { mPM (44) }\end{array}$ & - & $\begin{array}{l}\text { unaffected mRNA } \\
\text { IEC-18 (56) }\end{array}$ & $\begin{array}{l}\uparrow \text { mRNA mBMDM (40) } \\
\uparrow \text { mRNA murine spleen (39) }\end{array}$ \\
\hline WNT6 & $\begin{array}{l}\uparrow \text { mRNA Mtb mBMDM } \\
(40) \\
\text { unaffected mRNA } \\
M \text {. bovis BCG } \\
\text { mPM (44) }\end{array}$ & $\begin{array}{l}\text { unaffected mRNA } \\
\text { mPM (44) } \\
\uparrow \text { mRNA L. vannamei } \\
\text { HP, unaffected LO, } \\
\text { HT (46) }\end{array}$ & $\begin{array}{l}\downarrow \text { mRNA murine } \\
\text { S. pneumoniae } \\
\Delta \text { pep27 lung tissue } \\
\text { (51) }\end{array}$ & $\uparrow$ mRNA THP-1 (42) & $\begin{array}{l}\text { unaffected mRNA } \\
\text { mPM (44) }\end{array}$ & - & $\uparrow$ mRNA mIEC (43) & $\begin{array}{l}\downarrow \text { mRNA murine spleen (39) } \\
\uparrow \text { mRNA mBMDM (40) }\end{array}$ \\
\hline WNT7A & $\begin{array}{l}\downarrow \text { Mtb murine lung } \\
\text { tissue (40) } \\
\text { unaffected mRNA } \\
\text { M. bovis BCG } \\
\text { mPM (44) }\end{array}$ & $\begin{array}{l}\text { unaffected mRNA } \\
\text { mPM (44) } \\
\text { unaffected mRNA } \\
\text { (LvWnt7) L. vannamei } \\
\text { HP, LO, HT (46) }\end{array}$ & $\begin{array}{l}\uparrow \text { mRNA murine } \\
\text { S. pneumoniae } \\
\Delta \text { pep27 lung tissue } \\
\text { (51) }\end{array}$ & n.d. mRNA THP-1 (42) & $\begin{array}{l}\text { unaffected mRNA } \\
\text { mPM (44) }\end{array}$ & - & - & $\begin{array}{l}\text { n.d. mRNA mBMDM (40) } \\
\text { n.d. mRNA murine } \\
\text { spleen (39) }\end{array}$ \\
\hline WNT7B & $\begin{array}{l}\text { unaffected mRNA Mtb } \\
\text { murine lung tissue (40) } \\
\text { unaffected mRNA } \\
\text { M. bovis BCG } \\
\text { mPM (44) }\end{array}$ & $\begin{array}{l}\text { unaffected mRNA } \\
\text { mPM (44) } \\
\text { unaffected mRNA } \\
\text { (LvWnt7) L. vannamei } \\
\text { HP, LO, HT (46) }\end{array}$ & $\begin{array}{l}\uparrow \text { mRNA murine } \\
S . \text { pneumoniae } \\
\Delta \text { pep27 lung tissue } \\
\text { (51) }\end{array}$ & $\downarrow$ mRNA THP- 1 (42) & $\begin{array}{l}\text { unaffected mRNA } \\
\text { mPM (44) }\end{array}$ & - & - & $\begin{array}{l}\text { n.d. mRNA mBMDM (40) } \\
\uparrow \text { mRNA fetal ovine lungs } \\
\text { (49) } \\
\text { n.d. mRNA murine } \\
\text { spleen (39) }\end{array}$ \\
\hline WNTBA & $\begin{array}{l}\downarrow \text { mRNA Mtb murine } \\
\text { lung tissue (40) } \\
\text { unaffected mRNA } \\
\text { M. bovis BCG } \\
\text { mPM (44) }\end{array}$ & $\begin{array}{l}\text { unaffected mRNA } \\
\text { mPM (44) } \\
\text { unaffected mRNA } \\
\text { (LvWnt8) L. vannamei } \\
\text { HP, LO, HT (46) }\end{array}$ & - & unaffected THP-1 (42) & $\begin{array}{l}\text { unaffected mRNA } \\
\text { mPM (44) }\end{array}$ & - & - & $\begin{array}{l}\text { n.d. mRNA mBMDM (40) } \\
\text { n.d. mRNA murine } \\
\text { spleen (39) }\end{array}$ \\
\hline WNT8B & $\begin{array}{l}\downarrow \text { mRNA Mtb murine } \\
\text { lung tissue ( } 40 \text { ) } \\
\text { unaffected mRNA } \\
\text { M. bovis BCG } \\
\text { mPM (44) }\end{array}$ & $\begin{array}{l}\text { unaffected mRNA } \\
\text { mPM (44) } \\
\text { unaffected mRNA } \\
\text { (LvWnt8) L. vannamei } \\
\text { HP, LO, HT (46) }\end{array}$ & - & n.d. mRNA THP-1 (42) & $\begin{array}{l}\text { unaffected mRNA } \\
\text { mPM (44) }\end{array}$ & - & - & $\begin{array}{l}\text { n.d. mRNA murine } \\
\text { spleen (39) }\end{array}$ \\
\hline WNT9A & $\begin{array}{l}\downarrow \text { mRNA Mtb murine } \\
\text { lung tissue (40) } \\
\text { unaffected mRNA } \\
\text { M. bovis BCG } \\
\text { mPM (44) }\end{array}$ & $\begin{array}{l}\text { unaffected mRNA } \\
\text { mPM (44) } \\
\uparrow \text { mRNA (LvWnt9) } \\
\text { L. vannamei lymphoid } \\
\text { organ (46) } \\
\text { unaffected mRNA } \\
\text { (LvWnt9) L. vannamei } \\
\text { HP, LO, HT (46) }\end{array}$ & $\begin{array}{l}\downarrow \text { mRNA murine } \\
\text { S. pneumoniae } \\
\Delta \text { pep27 lung tissue } \\
\text { (51) }\end{array}$ & $\begin{array}{l}\text { unaffected mRNA } \\
\text { THP-1 (42) }\end{array}$ & $\begin{array}{l}\text { unaffected mRNA } \\
\text { mPM (44) }\end{array}$ & - & $\uparrow$ mRNA mIEC (43) & $\begin{array}{l}\text { n.d. mRNA murine } \\
\text { spleen (39) }\end{array}$ \\
\hline WNT9B & $\begin{array}{l}\downarrow \text { mRNA Mtb murine } \\
\text { lung tissue (40) } \\
\text { unaffected mRNA } \\
\text { M. bovis BCG } \\
\text { mPM (44) }\end{array}$ & $\begin{array}{l}\text { unaffected mRNA } \\
\text { mPM (44) } \\
\uparrow \text { mRNA (LvWnt9) } \\
\text { L. vannamei lymphoid } \\
\text { organ (46) } \\
\text { unaffected mRNA } \\
\text { (LvWnt9) L. vannamei } \\
\text { HP, LO, HT (46) }\end{array}$ & $\begin{array}{l}\downarrow \text { mRNA murine } \\
\text { S. pneumoniae } \\
\Delta \text { pep27 lung tissue } \\
\text { (51) }\end{array}$ & n.d. mRNA THP-1 (42) & $\begin{array}{l}\text { unaffected mRNA } \\
\text { mPM (44) }\end{array}$ & - & - & $\begin{array}{l}\text { n.d. mRNA murine } \\
\text { spleen (39) }\end{array}$ \\
\hline
\end{tabular}


TABLE 1 | Continued

\begin{tabular}{|c|c|c|c|c|c|c|c|c|}
\hline & Mycobacterium sp. & S. aureus & S. pneumoniae & E. chaffeensis & E. coli & $P$. aeruginosa & S. Typhimurium & LPS \\
\hline WNT10A & $\begin{array}{l}\uparrow \text { mRNA Mtb murine } \\
\text { lung tissue (40) } \\
\downarrow \text { mRNA M. marinum } \\
\text { zebrafish (54) }\end{array}$ & $\begin{array}{l}\text { unaffected mRNA } \\
(\text { LVWnt10) L. vannamei } \\
\text { HP, LO, HT (46) }\end{array}$ & - & $\uparrow$ mRNA THP-1 (42) & $\begin{array}{l}\text { unaffected mRNA } \\
\text { mPM (44) }\end{array}$ & - & - & $\begin{array}{l}\uparrow \text { mRNA murine spleen (39) } \\
\text { unaffected mRNA } \\
\text { mBMDM (40) }\end{array}$ \\
\hline WNT10B & $\begin{array}{l}\downarrow \text { mRNA } M \text { tb murine } \\
\text { lung tissue ( } 40 \text { ) } \\
\text { unaffected mRNA } \\
\text { M. bovis BCG } \\
\text { mPM (44) }\end{array}$ & $\begin{array}{l}\text { unaffected mRNA } \\
\text { mPM (44) } \\
\text { unaffected mRNA } \\
(\text { LWWnt10) L. vannamei } \\
\text { HP, LO, HT (46) }\end{array}$ & - & n.d. mRNA THP-1 (42) & $\begin{array}{l}\text { unaffected mRNA } \\
\text { mPM (44) }\end{array}$ & - & $\begin{array}{l}\text { unaffected mRNA } \\
\text { IEC-18 (50) }\end{array}$ & $\begin{array}{l}\uparrow \text { mRNA murine spleen (39) } \\
\uparrow \text { mRNA mBMDM (40) }\end{array}$ \\
\hline WNT11 & $\begin{array}{l}\text { unaffected mRNA } \\
\text { M. bovis BCG } \\
\text { mPM (44) }\end{array}$ & $\begin{array}{l}\text { unaffected mRNA } \\
\text { mPM (44) } \\
\text { unaffected mRNA } \\
\text { L. vannamei HP, LO, } \\
\text { HT (46) }\end{array}$ & - & $\begin{array}{l}\text { unaffected mRNA } \\
\text { THP-1 (42) }\end{array}$ & $\begin{array}{l}\text { unaffected mRNA } \\
\text { mPM (44) }\end{array}$ & - & $\begin{array}{l}\uparrow \text { mRNA and protein } \\
\text { IEC-18 (56) }\end{array}$ & $\begin{array}{l}\text { unaffected mBMDM (40) } \\
\uparrow \text { mRNA murine spleen (39) }\end{array}$ \\
\hline WNT16 & $\begin{array}{l}\downarrow \text { mRNA Mtb murine } \\
\text { lung tissue (40) } \\
\downarrow \text { mRNA M. marinum } \\
\text { zebrafish (54) }\end{array}$ & $\begin{array}{l}\text { unaffected mRNA } \\
\text { L. vannamei HP, LO, } \\
\text { HT (46) }\end{array}$ & - & n.d. mRNA THP-1 (42) & $\begin{array}{l}\text { unaffected mRNA } \\
\text { mPM (44) }\end{array}$ & - & - & $\begin{array}{l}\text { unaffected mRNA murine } \\
\text { spleen (39) }\end{array}$ \\
\hline $\begin{array}{l}\text { Effects } \\
\text { not } \\
\text { specific } \\
\text { to } \\
\text { individual } \\
\text { WNT } \\
\text { proteins }\end{array}$ & $\begin{array}{l}\uparrow \text { Fzd1 Mtb murine } \\
\text { lung tissue and } \\
\text { mBMDM (41) } \\
\uparrow \text { Fzd4, Lrp5, } \beta \text {-catenin } \\
\text { stabilization through } \\
\text { GSK3 phosphorylation } \\
\text { in M. bovis BCG mPM } \\
\text { (44) } \\
\downarrow \text { Axin2, Dv/3, } \\
\text { Fzd8,9,10 } \uparrow \text { Dv12 } \\
\text { M. marinum } \\
\text { zebrafish (54) }\end{array}$ & $\begin{array}{l}\downarrow \text { mom-5, mig-1 (FZD } \\
\text { homologues) } \\
\text { C. elegans IEC (45) } \\
\uparrow \text { Fzd4 m. PM (44) } \\
\uparrow \text { mRNA LvWntA } \\
\text { L. vannamei HP, } \\
\text { LO (46) }\end{array}$ & $\begin{array}{l}\downarrow \beta \text {-catenin activity } \\
\text { murine lung tissue (62) }\end{array}$ & $\begin{array}{l}\downarrow F Z D 7 \uparrow F Z D 5,9 \downarrow \\
D K K 3 \uparrow s F R P 2 \\
\text { THP-1 (42) }\end{array}$ & - & $\begin{array}{l}\downarrow \text { Ctnnb1 } \\
\text { RAW264.7 (63) }\end{array}$ & $\begin{array}{l}\beta \text {-catenin degradation } \\
\text { IEC-18 (64) } \\
\uparrow F z d 4,6,9, F z d 3,10 \\
\text { unaffected IEC-18 (50) } \\
\uparrow F Z D 2,7,8 \text { FZD5 } \\
\text { unaffected HCT116 } \\
\text { (56) } \\
\uparrow F z d 4 \text { mPM (44) }\end{array}$ & $\begin{array}{l}\uparrow \text { Fzd1, 5, Wisp 1, } \beta \text {-catenin } \\
\downarrow \text { Fzd7, } 8 \text { Fzd3, 6, 9, and } 10 \\
\text { unaffected murine spleen } \\
\text { (39) } \\
\downarrow \text { Ctnnb1 fetal ovine lungs } \\
\text { (49) } \\
\uparrow \text { LRP6 phosphorylation } \\
\text { BEAS-2B (53) } \\
\uparrow D V L 3 \text { hMDM (34) }\end{array}$ \\
\hline
\end{tabular}

MRNA or protein expression of WNT ligands and signaling components in response to infection or LPS exposure. $\uparrow$, upregulation; $\downarrow$, downregulation; -, indicative of no data; n.d., not detectable; protein, protein expression; mRNA, mRNA expression; $m$, murine; $h$, human; PM, peritoneal macrophages; BMDM, bone marrow-derived macrophages; IEC, intestinal epithelial cells; MDM, monocyte-derived macrophages; PBMC, peripheral blood mononuclear cells; SMC, spleen mononuclear cells; HP, hepatopancreas; LO, lymphoid organs; HT, hemocytes; Mtb, Mycobacterium tuberculosis. 
analyzed (44). Decreased Wnt5a protein and decreased Ctnnb1 mRNA expression in the mouse macrophage cell line RAW264.7 have also been reported upon infection with Pseudomonas (P.) aeruginosa (57) (63).

While several studies reported WNT5A expression to be responsive to macrophage encounter with Gram-negative bacterial pathogens, it remains to be defined whether opposing directions of the regulation of WNT5A expression reflect pathogen-specific responses, cell-type-dependent variations, or species-specific differences between humans and mice. Some indication that the latter apect might indeed be of importance comes from studies of macrophages stimulated with lipopolysaccharide (LPS), a major cell wall component of Gram-negative bacteria. Increased WNT5A expression has been noted in LPS-stimulated human monocytes, the human monocytic THP-1 cell line, as well as human bronchial epithelial BEAS-2B cells $(19,34,53,60,61)$. LPS-induced WNT5A expression in human macrophages occured downstream of Toll-like receptor signaling and nuclear factor kappa B $(\mathrm{NF}-\kappa \mathrm{B})$ activation, and was amplified by inflammatory cytokines such as tumor necrosis factor (TNF) and interferon $\gamma(\operatorname{IFN} \gamma)(19,34,60)$. In contrast, LPS stimulation did not significantly increase the relatively low $W n t 5 a$ mRNA expression of mouse bone marrow-derived macrophages (40), yet LPS stimulation did enhance Wnt5a mRNA expression by mouse RAW264.7 macrophages (37). Nevertheless, the amplitude of the WNT5A response might also be governed by the nature of the invading bacterial pathogen as suggested by observations that Porphyromonas gingivalis LPS induced WNT5A mRNA expression in THP-1 cells to a greater extent compared to $E$. coli-derived LPS (60).

Importantly, however, the LPS-induced WNT response encompasses more than WNT5A. LPS stimulation elevated expression of WNT3 in human monocyte-derived macrophages (52), and WNT1 in differentiated human THP-1 cells and murine bone marrow-derived macrophages $(40,48)$. The latter cells also displayed increased expression of $W n t 2 b$, Wnt5b, $W n t 6$, and Wnt10b upon LPS stimulation, whereas expression of $W n t 5 a, W n t 10 a$, and $W n t 11$ remained unchanged, and expression of the remaining Wnt genes was below the detection limit (40). Systemic challenge of mice with a sub-lethal dose of LPS in vivo induced rapid elevation of Wnt5b, Wnt10a, Wnt10b, Wnt11, Fzd1, and Fzd5 mRNA expression in spleen tissue, accompanied by elevated expression of the WNT target gene Wisp1. In contrast, expression of Wnt6, Fzd7, and Fzd8 was decreased, whereas Wnt3, Wnt4, Wnt5a, Wnt16, Fzd3, Fzd6, Fzd9, and Fzd10 were not differentially expressed (39). In an ovine model of fetal intra-amniotic LPS exposure, elevated expression of $W n t 7 b$, and reduced mRNA expression of Wnt1, Wnt2, Wnt4, and Ctnnb1 were observed in fetal lung tissue (49).

With patterns beginning to emerge in the WNT response to Gram-negative bacteria (e.g., WNT5A expression by macrophages), more detailed insight is required to delineate the impact of cell type-, species-, and pathogen-specific contributions to the amplitude and composition of infection-associated WNT responses.

\section{Gram-Positive Bacteria}

WNT responses upon infection with Gram-positive bacteria are just beginning to be explored (Table 1). Staphylococcus (S.) aureus infection of Drosophila melanogaster led to enhanced expression of Wnt4 (55). Expression of other WNT ligands was not determined in this study, leaving it to be determined how S. aureus, and other pathogens, affect WNT expression in Drosophila. S. aureus infection of Caenorhabditis elegans induced elevated expression of the WNT2 homolog $c w n-2$, and suppressed expression of the WNT1 homolog mom-2 and the FZD homolog mom-5 (45). A comprehensive analysis of WNT expression in the Pacific white shrimp Litopenaeus vannamei revealed pronounced upregulation of the mRNA expression of multiple WNT ligands, including LvWnt5, LvWnt6, LvWnt9, and $L v W n t A$ in different organs upon $S$. aureus infection (46). Expression of $W n t 5 a$ and Fzd4 by murine macrophages marginally increased upon infection with $S$. aureus (44). In contrast, infection of RAW264.7 mouse macrophages with Streptococcus (S). pneumoniae has been reported to suppress Wnt5a protein expression (57). Sequencing analyses of lung tissue of mice vaccinated intranasally with $S$. pneumoniae deficient for the autolysis-inducing factor pep27 revealed enhanced expression of Wnt4, Wnt5b, Wnt7a, and $W n t 7 b$, and impaired Wnt2b, Wnt3, Wnt6, Wnt9a, and Wnt $9 b$ mRNA expression (51). Kinase activity profiling in mouse lung tissue of $S$. pneumoniae-infected mice indicated a reduction in $\beta$-cateninstabilizing signals associated with a decrease in $\beta$-catenin protein expression (62). Thus, due to the paucity of information it is currently largely unknown if host cell encounter with pathogenic Gram-positive bacteria directly modulates WNT responses and signaling capabilities.

\section{Mycobacteria}

Mycobacterial infections induce significant alterations in the expression of WNT signaling components in infected tissues of a variety of host organisms (Table 1). Macrophage-associated WNT5A expression was initially described in tuberculosis lung granulomas (34), and WNT5A and FZD4 mRNA expression was significantly elevated in peripheral blood mononuclear cells of tuberculosis patients (44). Mycobacterium (M.) tuberculosis infection of C57BL/6 mice enhanced lung mRNA expression of Wnt1, Wnt6, Wnt10a, Fzd1, and Fzd5, while reducing expression of Wnt2, Wnt2b, Wnt3a, Wnt4, Wnt5a, Wnt7a, Wnt8a, Wnt10b, as well as Fzd3, Fzd7, Fzd8, Fzd9, and Fzd10 $(40,41)$. M. marinum infection of zebrafish enhanced expression of $w n t 5 a$, yet suppressed expression of multiple other WNT ligands, receptors and WNT pathway regulators (54). Regulation into opposing directions was noted for some WNT network components, depending on the virulence of the infecting $M$. marinum strain (54). Macrophages are major host cells for mycobacteria and have been identified as a significant source of WNT expression during mycobacterial infection. In vitro studies showed that infection of monocytes and macrophages of human and mouse origin with mycobacteria across a virulence spectrum (M. tuberculosis, M. avium, M. bovis Bacillus Calmette-Guérin) greatly enhanced expression of $\operatorname{WNT5A}(34,44)$. Importantly, expression and induction of WNT5A in human macrophages 
was more pronounced compared to mouse cells. In $M$. tuberculosis-infected mice, expression of Wnt6 was localized to macrophages in lung granulomas, and Wnt6 mRNA expression was significantly elevated in murine bone marrow derived macrophages infected with M. tuberculosis or M. avium (40). Taken together, the experimental evidence to date suggests that upregulation of WNT5A by mycobacteria-infected macrophages may be evolutionarily conserved between humans, mice and possibly other species. Nevertheless, expression of other WNT ligands by infected macrophages remains to be explored more systematically across species. Moreover, WNT/WNT receptor expression in infected tissues requires cellular context for more detailed understanding of where WNT responses occur upon encounter of pathogenic mycobacteria.

\section{Toward Defining Patterns in the Host WNT Response to Bacterial Infections}

A WNT response consistently reported for human, and to some extent murine, macrophages to diverse microbial challenges appears to be regulation of WNT5A expression. Yet, as it becomes clear that host WNT responses to bacterial infection reach well beyond differential expression of WNT5A, it will be essential to delineate whether patterns of WNT pathway activity are stereotypical responses of distinct host cell types and tissues to microbial insult, and/or how these responses are defined by the nature of the invading pathogen. With increasing insights into WNT responses to infection arises the need to understand WNT responses in human disease. Studies in patients with severe sepsis and septic shock highlight the complex nature of the host WNT response to microbial insult. Comparisons of blood gene expression patterns in patients with septic shock compared to healthy controls, revealed elevated expression of $W N T 5 B$ and $W N T 11$, whereas the expression of WNT1, WNT2B, WNT3, WNT6, WNT7A, WNT9A, WNT10A, WNT10B, and WNT16 was significantly reduced (39). Patients with severe sepsis had elevated WNT5A serum levels, and patients with sepsis-associated acute respiratory distress syndrome displayed elevated WNT5A protein expression in lung tissue $(19,68,69)$. An increase of WNT5A protein serum concentrations appeared to correlate with disease progression, whereas a decrease was associated with recovery in critically ill sepsis patients (68). However, WNT5A mRNA expression in whole blood was very low and not significantly different between healthy controls and septic shock patients, whereas alterations in the expression of other WNT ligands was more readily detectable (39). Whether dynamic changes in the expression of WNT pathway components accompanying severe acute infections can be exploited for the development of easily assessible biomarkers remains to be determined. Signatures that might enable patient stratification or rapidly identify classes of causative bacteria are worth exploring.

\section{Protozoal and Fungal Infections}

WNT responses to infections with protozoa and fungi are less well-explored (Table 2). In mice intraperitoneally inoculated with the protozoan parasite Trypanosoma (T.) cruzi, protein expression of Wnt3a, Wnt5a, and $\beta$-catenin in splenic mononuclear cells increased with disease progression
(74). Similar patterns were observed for Wnt3a and Wnt5a mRNA and protein expression in murine bone marrow-derived macrophages (BMDMs) (74). In vitro experiments indicated enhanced expression of Wnt $3 a$ and Wnt5a, Fzd4, Fzd6, Fzd8, and Fzd9 upon T. cruzi infection of murine BMDMs. In contrast, Leishmania donovani infection of mouse RAW264.7 macrophages resulted in diminished expression of Wnt5a, whereas other WNT ligands and sigaling components were not assessed (80). In human corneas infected with the fungus Aspergillus (A.) fumigatus, WNT5A expression was found to be significantly higher than in uninfected corneal tissues. WNT5A mRNA and protein expression were also enhanced by A. fumigatus infection of human THP-1 macrophages (78). Murine peritoneal macrophages infected with Candida albicans, A. fumigatus, or A. flavus or stimulated with the fungal and bacterial cell wall component Curdlan displayed elevated Wnt5a expression (79). More comprehensive profiling of the WNT network will be required to assess the quality of WNT responses by protozoal and fungal infections and determine to what extent WNT expression and signaling are defined by the host cell vs. the nature of the encountered pathogen.

\section{Viral Infections}

WNT responses to viral infections have been studied in the context of a limited number of viral infections (Table 2). HIV infection elevated $W N T 2 B$ and $W N T 10 B$ expression by human primary astrocytes (71), whereas expression of WNT1, WNT3, WNT5B, WNT9A, WNT9B, and WNT16 remained unaffected, and WNT2, WNT3A, WNT4, WNT5A, WNT6, WNT7A, WNT7B, WNT8A, WNT8B, WNT10A, and WNT11 expression was below the detection limit of the assay (71). HIV infection of mouse neuronal cells of the spinal dorsal horn elevated Wnt5a mRNA expression (77). WNT5A expression was also upregulated in Epstein Barr virus (EBV)- infected nasopharyngeal carcinoma epithelial cells (75). Influenza A infection of mice resulted in impaired expression of Wnt2, Wnt3a, Wnt10b, Fzd2, Lrp4, and $T c f 3$ in infected lung tissues (72). Human cytomegalovirus (HCMV) infection of human foreskin fibroblasts was associated with WNT5A and WNT5B downregulation (76), whereas HCMV infection elevated WNT2 expression in human mesenchymal stem cells (73). HCMV infection of dermal fibroblasts, placental extravillous trophoblasts, and foreskin fibroblasts was associated with degradation of $\beta$-catenin (83). In contrast, $\beta$-catenin stabilization was observed in human B cells infected with EBV (86), vaccinia virus-infected HEK293T cells (87), hepatitis B virus-infected Huh7 cells (84), and hepatitis C virus-infected HEK293T cells (85). These reports indicate responsiveness of the WNT signaling network to viral infections. Modulation of $\beta$-catenin stabilization might be indicative of viral exploitation of host cell replication and apoptosis. Yet, the WNT responses associated with viral infection noted thus far show no discernible patterns, likely due to the paucity of comprehensive analyses. Systematic comparisons of host cells and different viral classes are required to assess whether there are WNT network signatures that are indicative of a viral infection. 


\section{WNT FUNCTIONS IN THE HOST RESPONSE TO INFECTION}

The realization that the WNT network is responsive to infections has driven significant interest in delineating its roles in host defense and immune responses. There is increasing evidence that WNT ligands (and other ligands for WNT receptors) contribute to the host control of phylogenetically diverse pathogens in non-vertebrates and vertebrates $(57,74,80$, 88 , 89). Some associations between polymorphisms in WNT network genes, and susceptibility and quality of the immune response to infection have been suggested (90-93). Professional antigen-presenting cells (APCs) such as macrophages and dendritic cells have been studied intensively as sources and targets of WNT ligands $(19,40,44,94,95)$. Roles for WNT ligands in orchestrating phagocytosis, antimicrobial defense and inflammatory cytokine responses have been indicated (Figure 3, Table 3) $(48,98,100)$. WNT ligands have also been implicated in the cellular differentiation and functional polarization of APCs and $\mathrm{T}$ cells, bridging of innate and adaptive immune responses $(34,94)$, and shaping lymphocyte functions (107-112).

\section{Considerations for Experimentation}

Experimental approaches to deciphering WNT ligand-driven immune functions include utilization of mouse models with genetic deletion of individual WNT ligands or receptors. Use of cell-specific deletion $(95,113)$ or heterozygous mice (40, 57) is often indicated due to the deleterious impact of global deletion of individual WNT ligands on embryonic development. SiRNA-mediated knock-down of endogenous WNT components $(104,114)$, interference with WNT/WNT receptor interactions using neutralizing antibodies and recombinant WNT regulators (e.g., sFRPs, DKK) $(34,115)$, as well as plasmid-based overexpression of WNT ligands, receptors and regulators (63, 116) are commonly utilized, in particular in in vitro cellbased studies. Conditioned media from WNT-overexpressing cells and recombinant WNT proteins have also been proven as valuable tools for deciphering WNT functions. Of note, some biological responses of innate immune cells observed upon exposure to recombinant WNT protein preparations have been attributed to Toll-like receptor activation, rather than known WNT receptors $(61,117)$. The biological importance of this requires further clarification.

As it becomes increasingly evident that multiple WNT ligands are differentially expressed in response to microbial insults, and that WNT ligands are likely to arise from different cellular sources during infection, strategies that broadly target the WNT response as opposed to individual WNT ligands are increasingly employed. Cell-targeted conditional deletion of WLS and PORCN in mouse models, and the use of small molecule

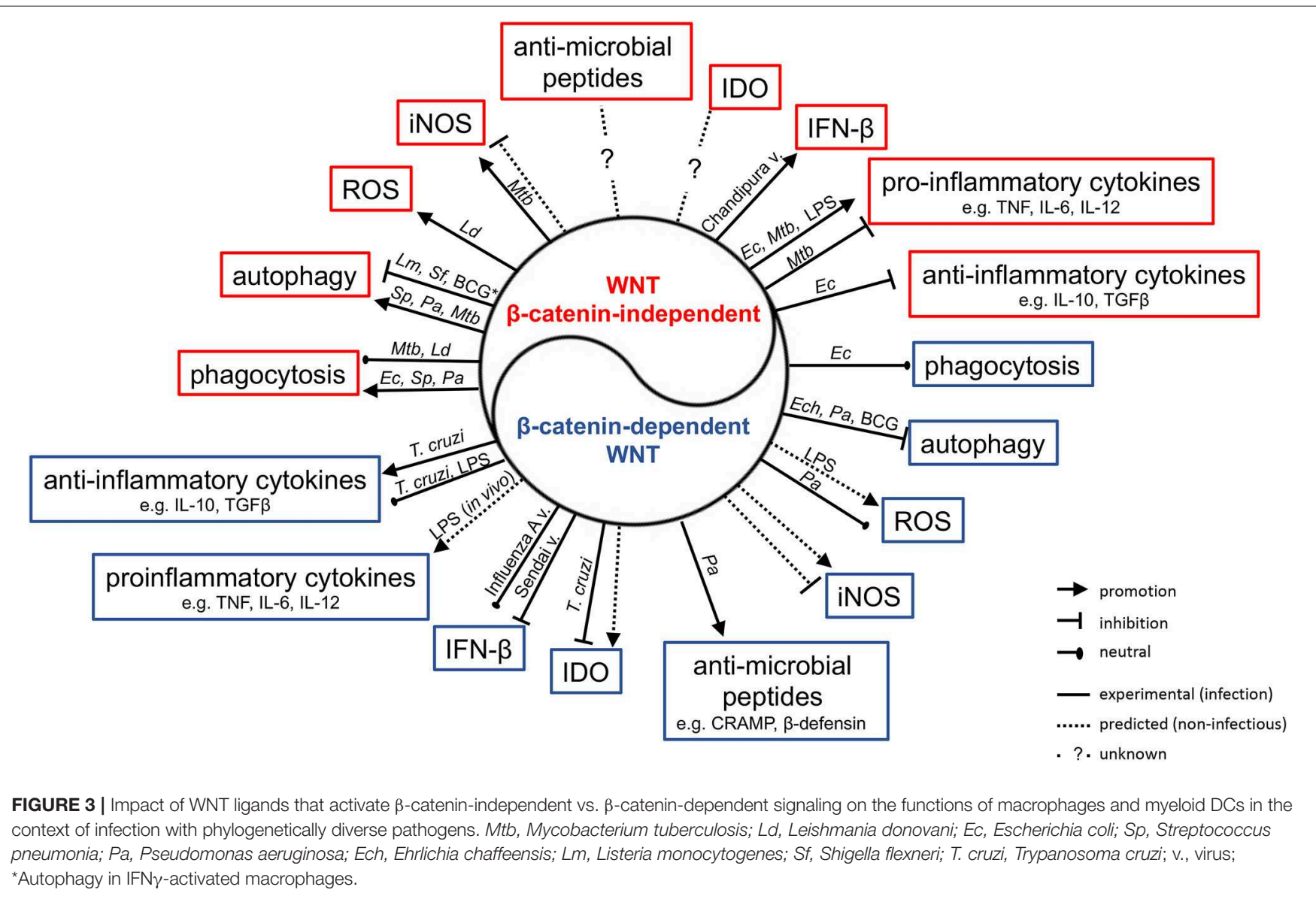


TABLE 2 | WNT responses induced by viral, fungal, and protozoal infection in experimental systems.

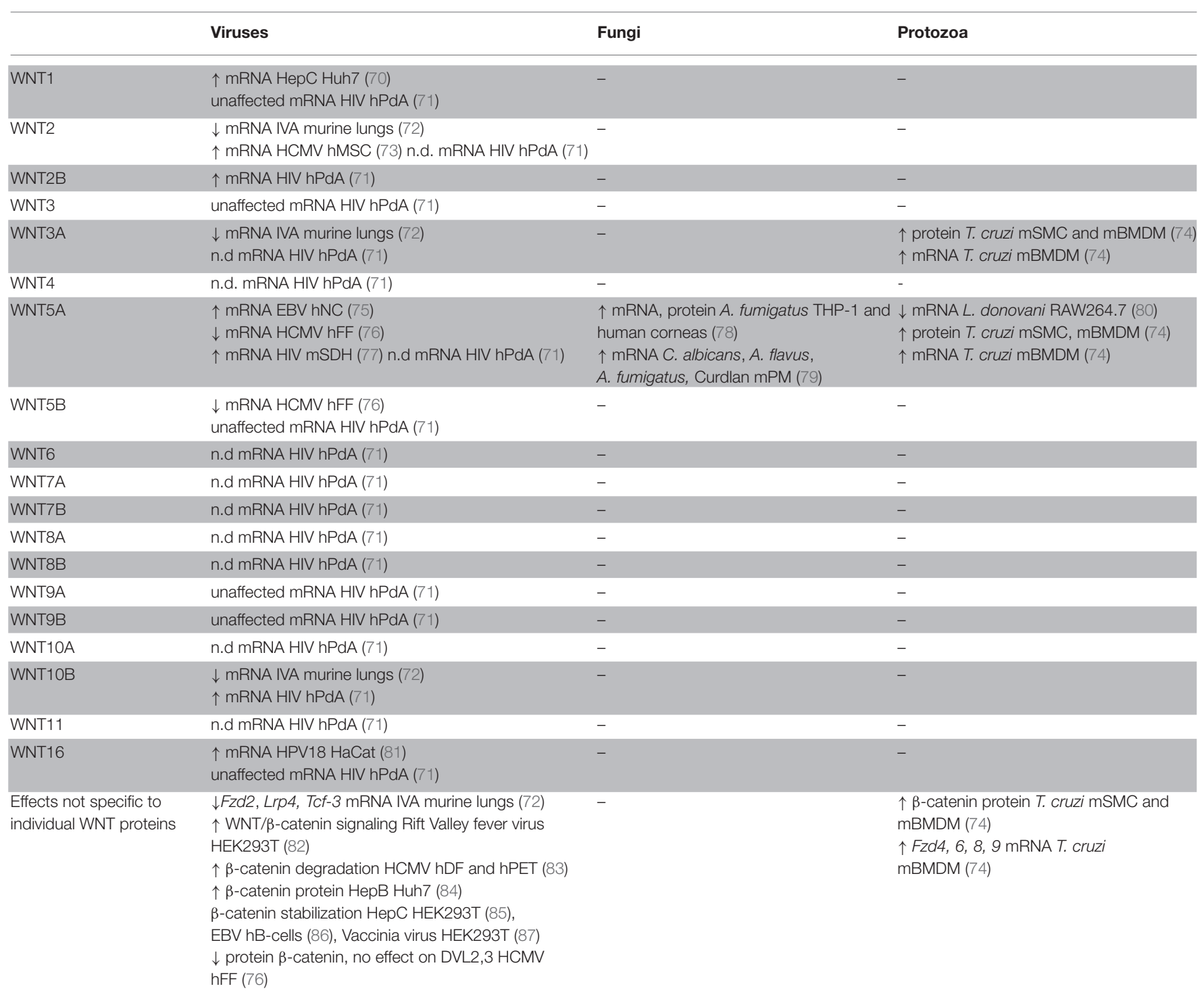

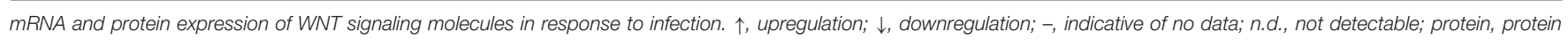

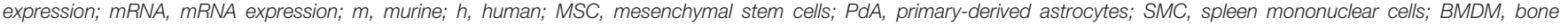
marrow-derived macrophages; NC, nasopharyngeal carcinoma; FF, foreskin fibroblasts; SDH, spinal dorsal horn; DF, dermal fibroblasts; PET, placental extravillous trophoblasts.

inhibitors targeting PORCN activity have proven useful for in vitro and in vivo studies (39, 42, 80, 98, 112, 118). Similarly, genetic and pharmacologic interference with $\beta$-catenin functions as a transcriptional co-activator have been employed to delineate functions of $\beta$-catenin-mediated WNT signaling $(39,112,119)$. It is important to note, however, that $\beta$-catenin stabilization is not exclusively indicative of WNT/WNT receptor engagement, and that microbial ligands and growth factors can induce $\beta$-catenin stabilization (120-122). Thus, here we chose to focus mainly on studies that link WNT ligands, their receptors and regulators with host defense to infection.

\section{Phagocytosis}

WNT-induced engagement of the actin cytoskeleton suggests that WNT ligands may play an active role in phagocytosis. Indeed, the D. melanogaster glypican dally is a co-receptor in wingless signaling and has been implicated in promoting phagocytosis of a non-pathogenic virus (white spot syndrome virus) by S2 phagocytes. Functional interactions of dally with frizzled 2 and wnt 2 in this process were deduced from gene expression analyses (96). In mouse RAW264.7 macrophage-like cells, it has been reported that exposure to $\mathrm{Wnt} 5 \mathrm{a}$-conditioned medium or recombinant Wnt5a enhanced uptake of non-pathogenic E. coli $\mathrm{DH} 5 \alpha$, as well as latex beads. In contrast, Wnt3aconditioned medium did not enhance phagocytosis $(80,98)$. Fzd5, as well as Rac-1, PI3K and IKK signaling were implicated in mediating the Wnt5a-driven phagocytic activity. Treatment with liposome-encapsulated Inhibitor of WNT Production-2 (IWP-2), a small-molecule PORCN inhibitor (123), impaired macrophage uptake of E. coli $\mathrm{DH} 5 \alpha$ (98). A follow-up study 
TABLE 3 | WNT functions in shaping host cell defense mechanism.

\begin{tabular}{|c|c|c|c|c|c|c|}
\hline & Phagocytosis & Autophagy & ROS & NOS & $\begin{array}{l}\text { Antimicrobial } \\
\text { peptides }\end{array}$ & Inflammatory cytokines \\
\hline WNT1 & - & - & - & $\begin{array}{l}\uparrow \text { iNOS LPS stimulated } \\
\text { THP-1 (48) }\end{array}$ & - & $\begin{array}{l}\uparrow \text { IL-6 } \uparrow \text { TNF LPS } \\
\text { stimulated THP-1 (48) }\end{array}$ \\
\hline WNT2 & $\begin{array}{l}\uparrow \text { virus uptake } D \text {. } \\
\text { melanogaster S2 (96) }\end{array}$ & - & - & - & - & - \\
\hline WNT2B & - & - & - & - & - & $\begin{array}{l}\downarrow \text { Sendai virus-induced } \\
\text { IFN } 11 \text { HEK293T (97) }\end{array}$ \\
\hline WNT3A & $\begin{array}{l}\text { unaffected E. coli DH5 } \alpha \\
\text { RAW264.7 (98) }\end{array}$ & $\begin{array}{l}\downarrow M . \text { bovis BCG } \\
\text { RAW.264.7 (99) }\end{array}$ & $\begin{array}{l}\text { unaffected } \\
P . \text { aeruginosa } \\
\text { RAW264.7 (100) } \\
\uparrow \text { NADPH oxidase and } \\
\text { hydrogen peroxide } \\
\text { HUVEC (101) }\end{array}$ & - & $\begin{array}{l}\uparrow \text { mRNA } \beta \text {-defensin } 1 \\
\text { and CRAMP } \\
\text { P. aeruginosa } \\
\text { RAW264.7 (100) }\end{array}$ & $\begin{array}{l}\downarrow \text { TNF, IL-6, IL-1 } \\
\text { P. aeruginosa RAW264.7 } \\
(100)\end{array}$ \\
\hline WNT5A & $\begin{array}{l}\uparrow \text { E. coli DH5 } \alpha \\
\text { RAW264.7 (98) } \\
\uparrow \text { latex beads } \\
\text { RAW264.7 (80) } \\
\uparrow \text { S. pneumoniae and } \\
P \text {. aeruginosa } \\
\text { RAW264.7 (57) } \\
\text { unaffected L. donovani } \\
\text { RAW264.7 (80) } \\
\text { unaffected Mtb } \\
\text { hMDM (102) }\end{array}$ & $\begin{array}{l}\uparrow P . \text { aeruginosa and } \\
\text { S. pneumoniae } \\
\text { RAW264.7 (57) } \uparrow \\
\text { Mtb infected hMDM } \\
\text { (102) } \downarrow M \text {. bovis BCG, } \\
\text { S. flexneri, L. } \\
\text { monocytogenes, but } \\
\text { not K. pneumoniae, } \\
\text { S. aureus or E. coli } \\
\text { (IFN } \gamma \text {-induced } \\
\text { autophagy) } \\
\text { RAW264.7 (103) }\end{array}$ & $\begin{array}{l}\uparrow N A D P H \\
\text { oxidase-mediated ROS } \\
\text { production RAW264.7 } \\
\text { (80) } \\
\uparrow R O S \uparrow \text { Wnt5a mPM } \\
\text { and RAW264.7 (79) }\end{array}$ & - & - & 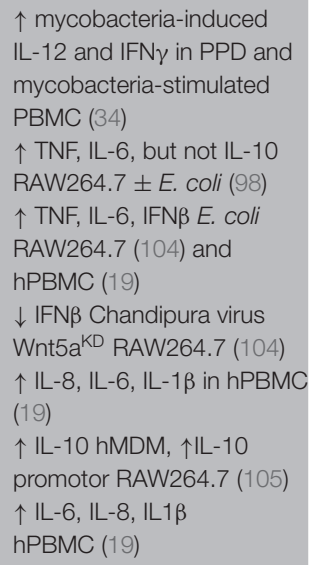 \\
\hline WNT6 & - & - & - & - & - & $\downarrow$ TNF Mtb mBMDM (40) \\
\hline WNT7A & $\downarrow$ mMDM (106) & - & - & - & - & $\begin{array}{l}\downarrow \mathbb{I L}-10, \mathrm{IL}-12 \uparrow \mathrm{NL}-6 \mathrm{mMDM} \\
(106)\end{array}$ \\
\hline WNT9B & - & - & - & - & - & $\begin{array}{l}\downarrow \text { IFN } \beta 1 \text { Sendai virus } \\
\text { HEK293T (97) }\end{array}$ \\
\hline WNT11 & - & - & - & - & - & ฟIL-8 mIEC (56) \\
\hline
\end{tabular}

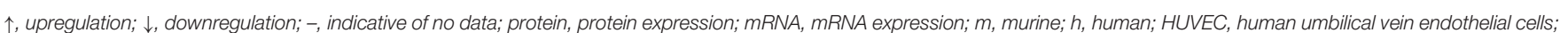

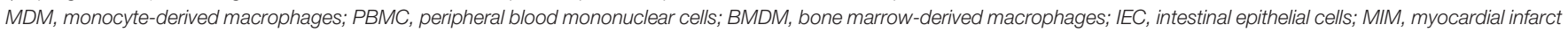
macrophages; Mtb, Mycobacterium tuberculosis.

described that exogenously added recombinant Wnt5a also enhanced RAW264.7 cell phagocytosis of S. pneumoniae (Grampositive) and $P$. aeruginosa (Gram-negative) mediated by Rac1 and Dvl (57). Mice pre-treated with IWP-2 displayed enhanced bacterial burden within peritoneal cells at $2 \mathrm{~h}$ postintraperitoneal infection, and within lung homogenates $5 \mathrm{~h}$ after intranasal infection with $P$. aeruginosa. Similarly, more viable $P$. aeruginosa were recovered from peritoneal cell lysates of $W n t 5 a^{+/-}$mice compared to $W n t 5 a^{+/+}$mice (57). These observations further suggest a role for $\mathrm{Wnt} 5 \mathrm{a}$, and potentially other WNT ligands in host cell uptake of $P$. aeruginosa. However, treatment of RAW264.7 cells with recombinant Wnt5a did not alter internalization of $L$. donovani (80), and siRNAmediated knock-down of endogenous WNT5A did not impair phagocytosis of $M$. tuberculosis by human monocyte-derived macrophages (102). Thus, the effects of WNT5A on phagocytosis of bacterial pathogens requires further investigation, including comparisons of extracellular alongside intracellular pathogens and macrophages of different origins.

E. chaffeensis is an obligate intracellular pathogen that infects mononuclear cells through caveolae-mediated endocytosis and resides in intracellular vesicles that retain characteristics of early endosomes (124). E. chaffeensis tandem repeat proteins (TRPs) are secreted effectors of $E$. chaffeensis that have been shown to interact with host cell proteins, including components of the WNT signaling network $(125,126)$. Phagocytosis of TRP120coated microspheres by human monocytic THP-1 cells was impaired by small molecules targeting intracellular signaling components that are also part of the WNT signaling network, such as $\beta$-catenin/TCF interactions (FH535), CamKII (KN93), and Rac-1 (NSC23766) (42). In contrast, a PORCN inhibitor (IWP-2) did not impair TRP120-microsphere phagocytosis, suggesting that secreted WNT proteins may not have been directly involved in driving this process. In contrast to phagocytic 
cells, WNT11 over-expression, but not WNT2 overexpression, by human intestinal epithelial HCT116 cells has been suggested to decrease invasion by Salmonella enterica Typhimurium (50, 56). The cellular mechanisms facilitating this protection are unknown and it remains to be established how induction of WNT11 expression by Salmonella infection might contribute to pathogenesis in vivo.

\section{Autophagy}

Several studies have begun to address how WNT ligands might affect the ability of host cells to control pathogenic bacteria. In the case of non-pathogenic E. coli DH5 $\alpha$, exogenous addition of Wnt5a enhanced phagocytosis, but did not alter the ability of RAW264.7 macrophages to rapidly kill the engulfed bacteria (98). In contrast, RAW264.7 macrophages exposed to recombinant Wnt5a displayed a more rapid decline in viable intracellular $S$. pneumoniae and $P$. aeruginosa within the first $2-3 \mathrm{~h}$ of infection. Wnt5a-induced killing within the first hours of infection was suggested to be mediated by Rac-1 and Dvl. Mechanistically, the authors implicated enhanced autophagy as the mechanism of Wnt5a-induced enhanced control of engulfed S. pneumoniae and $P$. aeruginosa (57). While $S$. pneumoniae is targeted by autophagy in non-phagocytic cells (127), the contribution of autophagy in macrophages to controlling this bacterium had not been reported previously. In contrast, the contributions of autophagy to macrophage control of $P$. aeruginosa require further clarification as beneficial effects for the host as well as the bacteria have been suggested $(63,128-131)$. It is noteworthy, however, that after the sharp initial decline of viable intracellular S. pneumoniae and P. aeruginosa in Wnt5a-treated RAW264.7 macrophages, from day 1 onwards the intracellular bacterial burden declined more slowly and at a similar rate in both Wnt5aand control-treated cells (57). Thus, the cellular mechanisms accelerating the initial bacterial killing might be transient, and could be specific to some pathogens as they did not affect macrophage killing of non-pathogenic E. coli DH5a (98). With Wnt5a expression reported to be suppressed by $S$. pneumoniae and $P$. aeruginosa infection of macrophages (57), roles of other WNT ligands responsive to infection (e.g., Wnt4, Wnt5b, Wnt7a, Wnt7b) (51) and the net-outcome of WNT signaling in infected cells will need further exploration. Of note, overexpression of $\beta$-catenin in RAW264.7 macrophages has been reported to accelerate killing of engulfed $P$. aeruginosa, which was associated with suppression of autophagy (63).

Beneficial or detrimental impact of WNT-autophagy-crosstalk might be defined by a pathogen's ability to exploit intracellular niches for replication and survival. Intracellular bacterial burden in E. chaffeensis-infected THP-1 cells was diminished when cells were exposed to IWP-2, as well as the $\beta$-catenin/TCF-1 inhibitor FH535, or the CamKII inhibitor KN93. Small interfering RNAmediated knock-down of WNT pathway components, including WNT5A, FZD5, FZD9, LRP6, CTNNB1, and DVL2 diminished intracellular bacterial burden over 1-2 days of infection, further supporting the notion that intracellular survival of E. chaffeensis in this cell line was facilitated by the action of endogenous WNT ligands (42). A subsequent study indicated that DVL signaling suppressed autophagy and phago-lysosomal maturation in E. chaffeensis-infected cells (132). WNT pathway activation (e.g. by Wnt5a) upon infection with $M$. bovis BCG has been reported to interfere with IFN $\gamma$-induced activation of autophagy in mouse macrophages, a process facilitated by arachidonate lipoxygenase. The same mechanisms have also been implicated for Shigella flexneri and Listeria monocytogenes infection (103). A recent study suggested that in human monocyte-derived macrophages infected with $M$. tuberculosis, WNT5A contributed to enhancing autophagy resulting in a small decrease in intracellular bacterial burden. In this study, WNT5A-mediated autophagy was suggested as an effector mechanism of IL-36r (102). However, as WNT5A expression in human macrophages is rapidly induced by $M$. tuberculosis infection (34), this mechanism might represent an amplification of the WNT5A response of these cells as indicated for other cytokines such as TNF (19). Exogenous addition of Wnt3a conditioned medium suppressed association of intracellular $M$. bovis BCG with autophagy machinery in RAW264.7 macrophages, which was associated with impaired mRNA expression of autophagy effectors (e.g., Atg5, Atg7, Atg12, p62) (99). With evidence for bi-directional regulation between WNT signaling and autophagy (133-135), and the notion that some pathogens might exploit this for their intracellular survival, the functional consequences of this crosstalk for pathogen control is an area for future pursuit.

\section{Reactive Radicals}

Additional cell-intrinsic host defense mechanisms that may be regulated by WNT signaling include the formation of reactive radicals. Treatment of RAW264.7 macrophages with recombinant Wnt5a induced NADPH oxidase-mediated ROS production, which has been suggested to contribute to the macrophage control of $L$. donovani (80). Exogenous addition of recombinant Wnt3a or Wnt3a-conditioned medium to human umbilical vein endothelial cells induced elevated expression of endothelial NADPH oxidase and production of hydrogen peroxide (101), and GSK3 $\beta$ has been implicated as a negative regulator of LPS-induced NADPH-oxidase 1 expression and production of reactive oxygen species production by macrophages (136). These observations could implicate $\beta$-catenin-stabilizing WNTs as drivers of ROS production. Yet, treatment of RAW264.7 macrophages with Wnt3aconditioned medium did not affect ROS production upon $P$. aeruginosa infection (100). Thus, contributions of WNT ligands, in particular endogenously expressed WNTs to ROS production as an anti-microbial defense mechanism require further investigation.

$W l s$-deficiency in BMDMs of $W l s^{\mathrm{fl} / \mathrm{fl}}$-Lyz2-Cre mice has been reported to significantly increase mRNA expression of inducible nitric oxide synthase (iNOS, encoded by Nos2) (137), a phenotype also observed in macrophages isolated from myocardial infarct tissue of $c f m s$-icre $W l s^{\mathrm{fl} / \mathrm{fl}}$ mice (138). This may be reflective of suppression of iNOS expression by autocrine/paracrine WNT signaling. The human iNOS promoter has TCF- 4 binding sites and Nos 2 expression and nitric oxide production were shown to be positively regulated by $\beta$-catenin and TCF-4 (139). These observations suggest that the balance of $\beta$-catenin-dependent and -independent WNT signaling could 
be important for fine-tuning iNOS expression and activity. Whether this bears consequences for pathogen control needs to be investigated. Nevertheless, enhanced iNOS expression by Wlsdeficient macrophages may indicate compensatory mechanisms associated with the inability to release WNT proteins from producing cells and significant elevation of WNT gene expression observed in these cells (137). However, such alterations in WNT expression may be cell specific as $\mathrm{F} 4 / 80^{+}$liver macrophages of

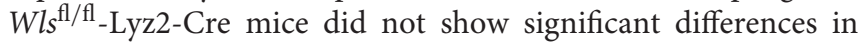
Wnt4 and Wnt6 expression (118).

With some indication that WNT ligands may determine a cell's ability for production of reactive oxygen and nitrogen species, there is also evidence that ROS and NO produced in response to microbial insult may regulate $\mathrm{WNT}$ responses. For example, peritoneal macrophages isolated from Nos $2^{-/-}$ mice showed lower induction of Wnt5a, Fzd4, and Lrp 5 mRNA expression upon $M$. bovis BCG infection compared to wild type control cells. Treatment with an NO-donor restored Wnt5a, Fzd4, and Lrp5 expression in Nos2-deficient macrophages (44), implicating reactive nitrogen species as potentiators of WNT signaling initiation. Dectin-1/Syk-mediated ROS production by murine RAW264.7 macrophages contributed to $\beta$-catenin stabilization (79), although how this might intersect with WNTdriven cellular activation remains to be explored.

\section{Antimicrobial Peptides}

Beta-catenin-stabilizing WNT ligands may also play a role in the expression of antimicrobial peptides. A recent study reported that Wnt3a-conditioned medium elevated the $P$. aeruginosa-induced mRNA expression of cathelicidin-related antimicrobial peptide (CRAMP) and $\beta$-defensin 1 in RAW264.7 mouse macrophages, which correlated with a small increase in bacterial killing by these cells (100). Stabilization of $\beta$-catenin has also been linked to production of the $\alpha$-defensins cryptdin- 1 and cryptdin- 6 by murine intestinal crypts (140). In C. elegans, it has been shown that expression of the antimicrobial peptide clec-60 (human homolog RegIII $\gamma$ ) upon $S$. aureus infection is dependent upon the $\beta$-catenin homolog bar-1 (45). These observations implicate $\beta$ catenin in the transcriptional control of a range of antimicrobial peptides. This encourage analyses on the potential roles of infection-responsive endogenous WNTs in the expression of antimicrobial peptides by infected cells.

\section{Tryptophan Metabolism}

Indoleamine 2,3dioxygenase (IDO) catalyzes the first ratelimiting step in the catabolism of the tryptophan for the formation of active metabolites (141). IDO activity is essential for host resistance to some infections where IDO activity limits the pathogen's access to the essential amino acid tryptophan $(142,143)$. The PORCN inhibitor IWP-L6 and the $\beta$-catenin inhibitor iCRT14 enhanced IDO expression and activity in $T$. cruzi-infected murine macrophages, which was associated with enhanced control of intracellular parasites (74). This suggests that endogenous WNT expression and associated $\beta$-catenin stabilization in T. cruzi-infected macrophages suppressed IDO expression in this context. It will be interesting to explore whether induction of $\mathrm{WNT} / \beta$-catenin signaling by $T$. cruzi is an active strategy of subverting host defense mechanisms. Importantly, $\beta$-catenin activity in $\mathrm{CD}_{11} \mathrm{c}^{+} \mathrm{APCs}$ has been associated with induction of IDO expression and the attainment of a tolerogenic phenotype in DCs $(144,145)$. Whether these apparent differences are reflective of the cellular context (macrophages vs. CD11c ${ }^{+}$ dendritic cells) or the immune responses (parasite infection vs. sterile inflammation) are worth further investigations.

\section{Anti-viral State and Type I Interferon Responses}

GSK3 $\beta$ activity and $\beta$-catenin functions have been implicated in the positive or negative regulation of type I interferon (IFN) responses associated with protection or susceptibility of cells to viral infection (82, 97, 146-152). In some studies, direct contributions of endogenous WNT ligands has been confirmed. For example, siRNA-mediated knock-down of Wnt5a in mouse bone marrow-derived macrophages and RAW264.7 cells impaired Chandipura virus-induced IFN $\beta$ production associated with enhanced viral load in infected cell cultures (104). WNT2B and WNT9B were identified as negative regulators of Sendai virus-induced interferon beta (IFN $\beta 1$ ) expression, and inhibition of GSK $3 \beta$-controlled virus-induced type I IFN responses in a $\beta$-catenin-dependent manner in a range of human cell lines and primary cells (97). SiRNA-mediated knockdown experiments in human bronchio-epithelial cells (HBECs) identified WNT5A and DKK1 as positive, and FZD5, DVL3, SFRP5, WNT7B, WNT9B as negative regulators of influenza A PR8 replication (114). Knock-down of WNT2 and WNT3 (but not WNT1, CTNNB1, or LEF1) impaired infection of HeLa cells by Dengue virus (153). Enhanced control of flaviviruses was associated with enhanced type I IFN signaling via interferon regulatory factor (IRF)-3 activation and interferon response gene expression. It was proposed that this was facilitated by crossregulation and physical interactions between TANK-binding kinase-1 (TBK-1, which phosphorylates IRF-3) and GSK3 $\beta$ (153). However, examples of $\beta$-catenin-stabilizing WNTs not affecting virus-induced interferon responses also exist (154).

\section{Inflammation}

WNT signaling has been ascribed both pro-inflammatory and immune-regulatory properties. The paradigm developed over the past decade or so suggests that WNT ligands triggering $\beta$-catenin-independent signaling exert pro-inflammatory functions, whereas WNT ligands driving $\beta$-catenin stabilization have anti-inflammatory or immune-modulatory effects. These emerging concepts of WNT ligands orchestrating inflammation and immune cell functions have been reviewed and commented on extensively over time $(19,120,155-163)$. Here we have chosen to specifically focus on examples for pro-inflammatory and regulatory effects of endogenous WNT ligands.

It is increasingly recognized that the WNT response upon infection or microbial challenge comprises complex changes across multiple WNT ligands, receptors and regulators (Tables 1, 2). Moreover, WNT receptors exhibit a degree of promiscuity for WNT ligands $(164,165)$. Thus, the concerted action of WNT ligands and the consequences for local and systemic inflammation in the context of infection require careful 
consideration. Use of small molecule inhibitors of PORCN (e.g., IWP-2) indicated net pro-inflammatory roles of WNT ligands in mouse models of LPS-induced endotoxemia and E. coli-induced bacterial peritonitis $(39,98)$. Moreover, two studies utilizing small molecule inhibitors of $\beta$-catenin functions as transcriptional co-activator (ICG001, iCRT3) independently revealed pro-inflammatory functions of $\beta$-catenin in LPSinduced endotoxemia and cecal ligation and puncture (CLP)induced peritonitis $(39,119)$. This challenged the current paradigm of anti-inflammatory roles of $\beta$-catenin stabilization and urges further studies to understand the contributions of $\beta$ catenin in different (immune) cells to inflammatory responses in vivo. Moreover, which of the individual WNT ligands responsive to infection are responsible for the pro-inflammatory functions in vivo, and what role selective downregulation of regulatory WNTs might play in this context remains to be explored in more detail.

Significant focus by some of the earliest studies has been on WNT5A, a WNT family member implicated in driving proinflammatory cytokine responses by myeloid cells via $\beta$-cateninindependent signaling $(19,34-36,166)$. Endogenous WNT5A has been shown to positively contribute to pro-inflammatory cytokine production by monocytes and macrophages in the context of Mycobacterium and E. coli infection, as well as LPS stimulation $(19,34,104)$. Knockdown of WNT5A in primary human bone marrow stromal cell also impaired basal and LPSinduced release of pro-inflammatory cytokines and chemokines (167). Inhibition of endogenous Wnt5a in a mouse model of HIV-induced neuroinflammation reduced gp120-induced proinflammatory cytokine responses in vivo (77). However, Wnt5a has also been implicated in impairing dendritic cell functions and creating an immune suppressive environment in a mouse melanoma model. Importantly, this was attributed to Wnt5a mediated $\beta$-catenin stabilization (168), which contrasts the proinflammatory roles of Wnt5a affected by $\beta$-catenin-independent signaling upon microbial challenge. This highlights that the receptor/signaling context rather than the WNT ligand might guide the functional outcome of WNT signaling.

Evidence for net anti-inflammatory functions of WNT ligands can be deduced from enhanced pro-inflammatory cytokine release and decreased release of regulatory TGF- $\beta$ by $T$. cruziinfected murine macrophages in the presence of PORCN (IWPL6) and $\beta$-catenin/TCF inhibitors (iCRT14) (74). In this study, it was noted that neither PORCN nor $\beta$-catenin inhibitors affected T. cruzi-induced IL-10 production by infected macrophages in vitro (74). Similar results were observed in an in vivo LPSinduced endotoxemia model (39). These observations highlight that IL-10 may not be susceptible to WNT regulation in all contexts.

An example of infection-induced expression of a specific endogenous WNT ligand being associated with suppression of pro-inflammatory cytokine responses comes from $M$. tuberculosis-infected mouse macrophages. Bone marrow-derived macrophages from Wnt6-deficient mice displayed elevated TNF expression and secretion upon M. tuberculosis infection (40). That immune-suppressive roles of individual WNT ligands could be vital for host survival upon bacterial infection has been demonstrated for WntD in Drosophila. WntD-deficiency rendered flies more susceptible to L. monocytogenes infection and this was attributed to WntD curbing lethal inflammation by negatively regulating expression of the inflammatory mediator edin via suppression of Dorsal, an NF-кB family member (88). Inhibition of intracellular cell signaling cascades that drive pro-inflammatory cytokine expression (e.g., NF- $\mathrm{B}$ ) has been implicated as one of the mechanisms by which $\beta$-cateninstabilizing WNT ligands negatively regulate inflammation (169, 170). Evidence on how this contributes to shaping cellular immune responses and inflammation during infection in complex in vivo settings will be invaluable to further affirm this regulatory feedback mechanism.

\section{FUNCTIONAL FATE OF MACROPHAGES AND DENDRITIC CELLS WITH IMPLICATIONS FOR T-CELL RESPONSES}

WNT ligands have been implicated in defining the functional polarization and differentiation of macrophages and dendritic cells. These innate immune cells are critical in shaping inflammation and antimicrobial defense, and in instructing adaptive immune responses in their role as professional antigen presenting cells (APCs).

\section{Macrophage Polarization}

Macrophages exhibit functional plasticity along a multidimensional spectrum directed by external and internal stimuli such as microbial products, cytokines, oxygen availability and cellular metabolism (171, 172). Accordingly, phenotypic classification of macrophages based on relative induction or suppression of the transcription of individual genes has limitations. Nevertheless, expression of iNOS is commonly associated with (M1-type) inflammatory macrophages, whereas elevation of arginase 1 (Arg1) expression has been associated with (M2-type) alternatively activated macrophages. Nevertheless, Arg1 activity is also found in M1 macrophages regulating NO production by iNOS (171). Wls deletion in resting mouse bone marrow-derived macrophages was accompanied by elevated expression of Nos2, Tnf, and Il6, and reduced expression of the M2-associated gene Mrc1 (macrophage mannose receptor), without affecting Arg1 expression (137). This suggests that basal Wls activity (and by inference the net impact of released WNT ligands) contributed toward M2 polarization of these macrophages. In contrast, several studies indicated that Arg1 expression is regulated by WNT ligands in macrophages upon pathogen encounter. For example, the PORCN inhibitor IWPL6, but not the $\beta$-catenin inhibitor iCRT14, decreased Arg1 expression in T. cruzi-infected mouse macrophages, yet without impacting production of reactive nitrogen intermediates (74). Wnt6-deficient macrophages expressed less Nos2 and Arg1 in response to $M$. tuberculosis infection, yet reactive nitrogen production was not impaired relative to wild type controls (40). Exogenous addition of Wnt3a-conditioned medium promoted the expression of Arg1 in M. tuberculosis-infected murine 
BMDMs (41). sFrp1-overexpression, which was accompanied by impaired $\beta$-catenin signaling, led to reduced expression of Arg1 and macrophage mannose receptor, CD206 (173). Albeit not evident of endogenous WNT ligands contributing to macrophage polarization, it is worth considering that in vitro exposure of macrophages to recombinant WNT ligands (including Wnt1, Wnt3a, Wnt5a, Wnt7a) have returned varying results on their ability to elicit phenotypic changes indicative of alternatively activated macrophages or macrophages tolerized against LPS activation $(61,105,106,117)$.

\section{Dendritic Cell Maturation and Functions}

The impact of exogenously added or endogenously released WNT ligands and contributions of $\beta$-catenin signaling on the expression of functional surface markers of DCs (e.g., MHCI and MHC-II, co-stimulatory molecules, PD-L1, PD-L2) and DC endocytic capacity has been analyzed in a number of studies returning varying results $(115,137,174-182)$. Such variability is likely governed by the use of cells from different species; differentiation and culture conditions; use of exogenous modulation through recombinant WNTs, conditioned media, WNT regulators vs. perturbation of endogenous WNT ligands and signaling events, for example by using small molecule inhibitors or genetic perturbations. Moreover, the utility of recombinant proteins and the possibility of alternative receptors interacting with WNT ligands requires further validation $(61,95$, $117,183,184)$.

Nevertheless, $\beta$-catenin activity in myeloid cells has emerged as a rheostat in immune-regulation and tolerance, specifically elucidated in in vivo models of autoimmunity, gut mucosal homeostasis and cancer $(95,120,162,183-185)$. Recent studies implicate direct roles for WNT ligands that act via engagement of LRP co-receptors in this regulatory mechanism. Selective deletion of LRP5/6 in CD11c ${ }^{+}$APCs (which includes DC and macrophage populations in the intestinal mucosa) rendered mice more susceptible to dextran sodium sulfate (DSS)-induced colitis $(95,144)$. This was associated with elevated expression of pro-inflammatory cytokines (e.g., TNF, IL-6, IL-1 $\beta$ ) and reduced expression of anti-inflammatory/regulatory effectors (e.g., IL-10, IDO), and functional bias toward fostering Th1 and Th17 responses at the detriment of $\mathrm{T}$ regulatory cells (Tregs). The microbiome has been implicated as a driver of inflammation in mice with LRP5/6-deficient CD11c ${ }^{+}$APCs with expression of a stabilized form of $\beta$-catenin specifically in $\mathrm{CD}_{11 \mathrm{c}^{+}}$APCs ameliorating disease pathology and proinflammatory responses in the DSS colitis model (144). Similar experimental approaches confirmed a regulatory role for $\beta$-catenin expression in CD11c ${ }^{+}$APCs in mouse models of experimental autoimmune encephalitis (EAE), collageninduced arthritis, and tumorigenesis $(94,183-185)$. It is interesting to note that the adjuvant utilized in the EAE model contains mycobacterial antigens and that LRP5/6-deficient DCs exhibited reduced pro-inflammatory and enhanced regulatory cytokine responses upon mycobacterial stimulation in vitro (94), suggesting that infection-associated WNT responses might direct APC functions in Treg vs. Th1 and Th17 differentiation.
In an OVA-expressing tumor model, Wnt1-overexpression by DCs was associated with reduced $\mathrm{T}$ cell receptor stimulation, granzyme B secretion and cytotoxicity by $\mathrm{CD} 8^{+} \mathrm{T}$ cells (186), whereas conditional knockout of LRP5/LRP6 in CD11c ${ }^{+}$cells resulted in an increase in granzyme $\mathrm{B}$ production by $\mathrm{CD} 8^{+}$ $\mathrm{T}$ cells (185). Thus, WNT-mediated activation of APCs also bears consequences for subsequent $\mathrm{T}$ cell functionality. Of note, there is some evidence indicating that WNT-mediated $\beta$-catenin signaling also orchestrates the differentiation of plasmacytoid DCs (187-190), but consequences for pDC functions remain to be explored.

The aforementioned studies support the view that $\beta$ catenin-stabilizing WNT signaling engaging LRP5/6 co-receptors can mediate an immune-regulatory profile of DC functions. In contrast, inducible deletion of Wnt5a and one of its receptors, Ror2, rendered mice more resistant to DSS-induced colitis (113). This was accompanied by diminished proinflammatory cytokine responses, including IL-12 expression, and selective impairment in the differentiation of IFN $\gamma$ producing $\mathrm{CD}^{+} \mathrm{T}$ cells, without impact on IL-17- and IL-10producing $\mathrm{CD}^{+} \mathrm{T}$ cells (113). It was implicated that Wnt5a in this context arose from non-hematopoietic cells such as fibroblasts, whereas Ror2 signaling occurred in the hematopoietic compartment including DCs. Nevertheless, cultured Wnt5adeficient and Ror2-deficient colonic DCs showed impaired proinflammatory cytokine profiles upon LPS stimulation including enhanced IL-12 production and increased responsiveness to IFN $\gamma$ (113). These observations support the notion of proinflammatory roles of Wnt5a expressed by myeloid cells. They also align with data indicating that myeloid cell-derived WNT5A, and likely other WNT ligands, bridge innate and adaptive immunity by perpetuating the IL-12-IFN $\gamma$ axis in $\mathrm{T}$ cell and natural killer $\mathrm{T}$ (NKT) cell responses $(34,112$, 174). Importantly, however, the roles Wnt5a plays in shaping DC functions may be defined by the receptor/signaling output. This is highlighted by findings that melanoma-derived Wnt5a effected a metabolic shift in DCs from glycolysis to oxidative phosphorylation, which was attributed to $\beta$-cateninand PPAR $\gamma$-mediated cellular activation. This resulted in tolerogenic DCs that promoted IDO activity and regulatory $\mathrm{T}$ cell differentiation. Relevance of this mechanism was translated into an in vivo melanoma model in mice (145). It will be important to delineate whether factors specific to the pathophysiological context (e.g., immune regulatory molecules, cytokine milieu) explain the apparently opposing outcomes of WNT exposure on DC functions in melanoma vs. inflammatory disorders.

\section{T Cell Functions During Infection}

Genetic deletion of $\beta$-catenin in $\mathrm{CD}_{11 c^{+}}$cells was associated with only a small increase in the frequency of $\mathrm{CD} 4^{+}$ $\mathrm{T}$ cells, but no significant changes in the frequency of $\mathrm{CD}^{+} \mathrm{T}$ cells, $\mathrm{TCR} \gamma \delta^{+} \mathrm{T}$ cells, NKT cells, Tregs, or $\mathrm{T}$ follicular helper cells were observed $(183,191)$. These findings suggest that $\beta$-catenin functions in $\mathrm{CD}_{11 \mathrm{c}^{+}}$ myeloid cells define the quality of $\mathrm{T}$ cell responses 
due to the functional capabilities of APCs, rather than by significantly affecting lymphocyte differentiation. Nevertheless, $\beta$-catenin and TCF activation play distinct roles in the development, differentiation and function of innate-like and adaptive lymphocytes, and direct contributions of WNT ligands to these processes have been shown $(110,192,193)$.

In a mouse model of lymphocytic choriomeningitis virus (LCMV) infection, TCF-1-deficiency had no effect on the expansion and functions (e.g., IFN $\gamma$ production and cytolysis) of effector CD8 ${ }^{+}$T cells $(194,195)$, whereas others reported an increase in effector $\mathrm{CD}^{+}$T cells associated with enhanced IFN $\gamma$ and TNF expression (196). In contrast to the apparently opposing observations for effector $\mathrm{T}$ cells, these studies consistently showed reduced numbers of memory $\mathrm{CD}^{+} \mathrm{T}$ cells, reduced IL-2 expression, and impaired expansion of memory cells upon rechallenge (194-196). However, it was suggested that these TCF-1-mediated effects may not be attributable to $\beta$ catenin functions, as conditional knockout of $\beta$-catenin in mature $\mathrm{T}$ cells did not affect memory $\mathrm{T}$ cell numbers or functions upon LCMV and L. monocytogenes infection (197). Yet, in a transgenic mouse model of constitutively activated $\beta$ catenin/TCF-1-signaling, an increased proportion of memory $\mathrm{CD}^{+} \mathrm{T}$ cells and increased IFN $\gamma$ expression during LCMV, vaccinia virus and $L$. monocytogenes infection were reported (198). These studies indicate that TCF-1 is likely required for $\mathrm{CD}^{+} \mathrm{T}$ cell memory formation and functions after infection. The role $\beta$-catenin might play in this and whether WNT ligands have a direct contribution to these signaling events requires further investigation.

In an in vitro system, depletion of WNT1, 2B, 3 and 5B from astrocyte-conditioned medium reduced the differentiation of $\mathrm{CD}^{+} \mathrm{T}$ cells toward a CD $4{ }^{\mathrm{dim}} \mathrm{CD} 8^{\text {bright }} \mathrm{T}$ phenotype in cultures of human peripheral blood mononuclear cells. CD ${ }^{\text {dim }} \mathrm{CD} 88^{\text {bright }}$ $\mathrm{T}$ cells in the central nervous system are thought to be effector memory $\mathrm{T}$ cells important in the control of HIV (71). While this study implicated direct involvement of WNT ligands in the formation of this $\mathrm{CD}^{+} \mathrm{T}$ cell subset, it remains to be determined whether WNT ligands mediated this differentiation by acting on the $\mathrm{CD}^{+} \mathrm{T}$ cells, or indirectly via APCs (e.g., by shaping the cytokine milieu). To our knowledge, there are thus far only very few links between WNT ligands and CD4 ${ }^{+} \mathrm{T}$ cell functions during infection. In a susceptible mouse model of Leishmania major infection, an inhibitor of Dkk1, which should increase $\mathrm{WNT} / \beta$-catenin signaling, exhibited reduced numbers of $\mathrm{CD}^{+}{ }^{+} \mathrm{T}$ cells in the draining lymph node, with subsequent reduced IL-4 and IL-10 expression after ex vivo stimulation (199). An in vitro study utilizing neutralizing antibodies against WNT5A and FZD5 showed impaired antigen-specific IFN $\gamma$ production by human PBMCs of antigen-experienced donors re-stimulated with $M$. tuberculosis antigen. As human T cells expressed FZD5, it was hypothesized that WNT signaling can facilitate memory $\mathrm{T}$ cell activation (34). However, these studies did not demonstrate that these effects were driven directly by WNT signaling in $\mathrm{CD}^{+} \mathrm{T}$ cells, nor did they exclude WNT effects on APC functions. Detailed analyses of the WNT receptor and WNT regulator repertoire of different $\mathrm{T}$ cell lineages and subsets should guide targeted interventions with WNT signaling events to delineate the roles infection-associated WNT responses play in shaping $\mathrm{T}$ cell effector and memory formation and functions.

\section{CONCLUDING REMARKS AND FUTURE PERSPECTIVES}

The WNT signaling network has been firmly established as an evolutionary conserved integral component of host responses to infection. In-depth understanding of how WNT ligands define immune cell functions is beginning to offer mechanistic insights into the contributions of WNT responses to pathogen control and inflammation. Experiments establishing how infectionassociated endogenous WNT responses shape immune cell functionality in vivo will be key to deciphering WNT functions in shaping complex immune responses. Thus far, macrophages and DCs, as well as $\mathrm{T}$ cells have been a major focus of delineating WNT-mediated immune functions. Knowledge of how WNT ligands shape the functions of other immune cells, including neutrophils, mast cells, natural killer cells, natural killer $\mathrm{T}$ cells, innate lymphoid cells, B cells, etc. is required to begin to understand the complexity of immune-related WNT responses.

Considering that the WNT signaling outcome is largely decided by the cellular context at the level of receptor engagement (20), functional redundancy of WNT ligands, or lack thereof, in orchestrating cellular responses of functionally diverse cells in complex tissue environments is an important factor. With a clearer understanding of the WNT receptor and WNT regulator repertoire expressed by different immune- and nonimmune cells in responses to infection, it will be important to determine if there are species-specific differences in the consequences of WNT exposure of functionally similar cells. This is especially critical when investing in utilizing animal models for understanding human pathology and calls for systematic analyses of WNT responses in infected tissues across different species. Reporter mice for WNT ligand and receptor expression as well as WNT signaling activity $(200,201)$ will be invaluable for the temporal and spatial documentation of WNT responses in complex in vivo settings, including infections. Comparisons with human specimens, wherever possible, will be critical.

While some consistent patterns of WNT responses begin to arise (e.g., WNT5A regulation in human macrophages), it remains largely unclear whether stereotypical WNT responses to infection exist regardless of the invading pathogen, or whether the nature of the pathogen dictates the WNT response. Comparative studies using phylogenetically diverse pathogens covering spectra of virulence and pathogenesis mechanisms will be essential to distinguish stereotypical and selective responses to microbial infection. In depth understanding of the molecular drivers and regulators of WNT ligand and receptor expression during infection will be invaluable in delineating which microbial factors drive WNT responses. Whereas our understanding of WNT responses and functions during viral and bacterial 
infections is taking shape, WNT contributions to parasitic and fungal infections remain to be explored in more breadth and depth. Knowledge of the investment of pathogens into actively manipulating the WNT signaling network (202-204) will inform our understanding of pathogenesis mechanisms and roles of WNT signaling in the host defense against infection. Such insights will be essential when exploring WNT response patterns as biological indicators supporting diagnosis, prognosis and choices for clinical management of infectious diseases (205).

Due to the central role of WNT signaling in maintaining tissue homeostasis, including epithelial barrier functions, consequences of immune-related WNT responses reach beyond leukocyte functions. Indications that WNT/WNT receptor interactions shape chemokine responses (186) and cellular metabolism (145) deserve particular attention in the context of immune responses to infection and beyond. Aberrant WNT expression and/or WNT signaling underlying carcinogenesis, fibrosis, and osteoporosis has generated considerable interest in pharmacologically targeting the WNT signaling network (206-209). Understanding the functional nature and temporal regulation of WNT responses in the host response to infection, and other immune settings, is essential for identifying therapeutic opportunities, but also potential risks of pharmacologically targeting the WNT signaling network.

\section{REFERENCES}

1. Routledge D, Scholpp S. Mechanisms of intercellular Wnt transport. Development. (2019). 146: dev176073. doi: 10.1242/dev. 176073

2. Clevers $H$, Nusse R. Wnt/ $\beta$-catenin signaling and disease. Cell. (2012) 149:1192-205. doi: 10.1016/j.cell.2012.05.012

3. Nusse R, Clevers H. Wnt/ $\beta$-catenin signaling, disease, and emerging therapeutic modalities. Cell. (2017) 169:985-99. doi: 10.1016/j.cell.2017.05.016

4. Logan CY, Nusse R. The Wnt signaling pathway in development and disease. Annu Rev Cell Dev Biol. (2004). 20:781-810. doi: 10.1146/annurev.cellbio.20.010403.113126

5. Steinhart Z, Angers S. Wnt signaling in development and tissue homeostasis. Development. (2018). 145:dev146589. doi: 10.1242/dev.146589

6. Ring A, Kim YM, Kahn M. Wnt/catenin signaling in adult stem cell physiology and disease. Stem Cell Rev. (2014) 10:512-25. doi: 10.1007/s12015-014-9515-2

7. Willert K, Brown JD, Danenberg E, Duncan AW, Weissman IL, Reya T, et al. Wnt proteins are lipid-modified and can act as stem cell growth factors. Nature. (2003) 423:448-52. doi: 10.1038/nature01611

8. Janda CY, Waghray D, Levin AM, Thomas C, Garcia KC. Structural basis of Wnt recognition by Frizzled. Science. (2012) 337:59-64. doi: 10.1126/science.1222879

9. Kurayoshi M, Yamamoto H, Izumi S, Kikuchi A. Post-translational palmitoylation and glycosylation of Wnt-5a are necessary for its signalling. Biochem J. (2007) 402:515-23. doi: 10.1042/BJ20061476

10. Banziger C, Soldini D, Schutt C, Zipperlen P, Hausmann G, Basler K. Wntless, a conserved membrane protein dedicated to the secretion of Wnt proteins from signaling cells. Cell. (2006) 125:509-22. doi: 10.1016/j.cell.2006.02.049

11. Bartscherer K, Pelte N, Ingelfinger D, Boutros M. Secretion of Wnt ligands requires Evi, a conserved transmembrane protein. Cell. (2006) 125:523-33. doi: 10.1016/j.cell.2006.04.009

12. Goodman RM, Thombre S, Firtina Z, Gray D, Betts D, Roebuck J, et al. Sprinter: a novel transmembrane protein required for $\mathrm{Wg}$

\section{AUTHOR CONTRIBUTIONS}

$\mathrm{JL}, \mathrm{JK}$, and $\mathrm{AB}$ wrote the manuscript. TT contributed sections to the manuscript. JL and $\mathrm{AB}$ conceived and designed figures and tables. All authors read and approved the final version of the manuscript.

\section{ACKNOWLEDGMENTS}

The authors acknowledge funding support for primary research projects related to the topic of this review by the Australian National Health and Medical Research Council (GNT1142456 AB), Australian Infectious Diseases Research Centre at The University of Queensland (AB), The University of Queensland Postgraduate Scholarship (JL), Postgraduate Scholarship through the Australia Awards Scholarships (TT), The University of Queensland Postdoctoral Research Fellowship (JK), The University of Queensland Early Career Researcher Grant (JK). Figures 1, 2 were created using Biorender.com.

We apologize to colleagues whose primary research work was not integrated into this review due to space constrains or whose contributions to this immense and rapidly growing field was inadvertently overlooked.

secretion and signaling. Development. (2006) 133:4901-11. doi: 10.1242/dev. 02674

13. Gasnereau I, Herr P, Chia PZ, Basler K, Gleeson PA. Identification of an endocytosis motif in an intracellular loop of Wntless protein, essential for its recycling and the control of Wnt protein signaling. J Biol Chem. (2011) 286:43324-33. doi: 10.1074/jbc.M111.307231

14. Langton PF, Kakugawa S, Vincent JP. Making, exporting, and modulating Wnts. Trends Cell Biol. (2016) 26:756-65. doi: 10.1016/j.tcb.2016.05.011

15. Kadiu I, Narayanasamy P, Dash PK, Zhang W, Gendelman HE. Biochemical and biologic characterization of exosomes and microvesicles as facilitators of HIV-1 infection in macrophages. J Immunol. (2012) 189:744-54. doi: $10.4049 /$ jimmunol.1102244

16. Singh PP, Smith VL, Karakousis PC, Schorey JS. Exosomes isolated from mycobacteria-infected mice or cultured macrophages can recruit and activate immune cells in vitro and in vivo. J Immunol. (2012) 189:777-85. doi: 10.4049/jimmunol.1103638

17. Giri PK, Schorey JS. Exosomes derived from M. Bovis BCG infected macrophages activate antigen-specific CD4+ and CD8+ T cells in vitro and in vivo. PLoS ONE. (2008). 3:e2461. doi: 10.1371/journal.pone.0002461

18. Bhatnagar S, Shinagawa K, Castellino FJ, Schorey JS. Exosomes released from macrophages infected with intracellular pathogens stimulate a proinflammatory response in vitro and in vivo. Blood. (2007) 110:3234-44. doi: 10.1182/blood-2007-03-079152

19. Pereira C, Schaer DJ, Bachli EB, Kurrer MO, Schoedon G. Wnt5A/CaMKII signaling contributes to the inflammatory response of macrophages and is a target for the antiinflammatory action of activated protein C and interleukin-10. Arterioscler Thromb Vasc Biol. (2008) 28:504-10. doi: 10.1161/ATVBAHA.107.157438

20. Niehrs C. The complex world of WNT receptor signalling. Nat Rev Mol Cell Biol. (2012) 13:767-79. doi: 10.1038/nrm3470

21. Mlodzik M. The dishevelled protein family: still rather a mystery after over 20 years of molecular studies. Curr Top Dev Biol. (2016). 117:75-91. doi: 10.1016/bs.ctdb.2015.11.027

22. Aberle H, Bauer A, Stappert J, Kispert A, Kemler R. beta-catenin is a target for the ubiquitin-proteasome pathway. EMBO J. (1997) 16:3797-804. doi: $10.1093 / \mathrm{emboj} / 16.13 .3797$ 
23. Kitagawa M, Hatakeyama S, Shirane M, Matsumoto M, Ishida N, Hattori K, et al. An F-box protein, FWD1, mediates ubiquitin-dependent proteolysis of beta-catenin. EMBO J. (1999) 18:2401-10. doi: 10.1093/emboj/18.9.2401

24. Acebron SP, Niehrs C. $\beta$-catenin-independent roles of Wnt/LRP6 signaling. Trends Cell Biol. (2016) 26:956-967. doi: 10.1016/j.tcb.2016.07.009

25. Jaffe AB, Hall A. Rho GTPases: biochemistry and biology. Annu Rev Cell Dev Biol. (2005). 21:247-69. doi: 10.1146/annurev.cellbio.21.020604.150721

26. Takai Y, Sasaki T, Matozaki T. Small GTP-binding proteins. Physiol Rev. (2001) 81:153-208. doi: 10.1152/physrev.2001.81.1.153

27. Sedgwick AE, D'Souza-Schorey C. Wnt signaling in cell motility and invasion: drawing parallels between development and cancer. Cancers. (2016) 8:E80. doi: 10.3390/cancers8090080

28. De A. Wnt/Ca2+ signaling pathway: a brief overview. Acta Biochim Biophys Sin. (2011) 43:745-56. doi: 10.1093/abbs/gmr079

29. Kakugawa S, Langton PF, Zebisch M, Howell S, Chang TH, Liu Y, et al. Notum deacylates Wnt proteins to suppress signalling activity. Nature. (2015) 519:187-92. doi: 10.1038/nature14259

30. Niehrs C. Function and biological roles of the Dickkopf family of Wnt modulators. Oncogene. (2006) 25:7469-81. doi: 10.1038/sj.onc.1210054

31. Cruciat CM, Niehrs C. Secreted and transmembrane wnt inhibitors and activators. Cold Spring Harb Perspect Biol. (2013). 5:a015081. doi: 10.1101/cshperspect.a015081

32. Hutchins EJ, Bronner ME. Draxin acts as a molecular rheostat of canonical Wnt signaling to control cranial neural crest EMT. J Cell Biol. (2018). 217:3683-97. doi: 10.1083/jcb.201709149

33. Hao HX, Jiang X, Cong F. Control of Wnt receptor turnover by R-spondinZNRF3/RNF43 signaling module and its dysregulation in cancer. Cancers. (2016). 8:E54. doi: 10.3390/cancers8060054.

34. Blumenthal A, Ehlers S, Lauber J, Buer J, Lange C, Goldmann T, et al. The wingless homolog WNT5A and its receptor Frizzled-5 regulate inflammatory responses of human mononuclear cells induced by microbial stimulation. Blood. (2006) 108:965-73. doi: 10.1182/blood-2005-12-5046

35. Pukrop T, Klemm F, Hagemann T, Gradl D, Schulz M, Siemes S, et al. Wnt $5 \mathrm{a}$ signaling is critical for macrophage-induced invasion of breast cancer cell lines. Proc Natl Acad Sci USA. (2006) 103:5454-9. doi: 10.1073/pnas.0509703103

36. Sen M, Lauterbach K, El-Gabalawy H, Firestein GS, Corr M, Carson DA. Expression and function of wingless and frizzled homologs in rheumatoid arthritis. Proc Natl Acad Sci USA. (2000) 97:2791-6. doi: 10.1073/pnas.050574297

37. Christman MA II, Goetz DJ, Dickerson E, McCall KD, Lewis CJ, Benencia $\mathrm{F}$, et al. Wnt5a is expressed in murine and human atherosclerotic lesions. Am J Physiol Heart Circ Physiol. (2008). 294:H2864-70. doi: 10.1152/ajpheart.00982.2007

38. Ouchi N, Higuchi A, Ohashi K, Oshima Y, Gokce N, Shibata R, et al. Sfrp5 is an anti-inflammatory adipokine that modulates metabolic dysfunction in obesity. Science. (2010) 329:454-7. doi: 10.1126/science.1188280

39. Gatica-Andrades M, Vagenas D, Kling J, Nguyen TK, Benham H, Thomas R, et al. WNT ligands contribute to the immune response during septic shock and amplify endotoxemia-driven inflammation in mice. Blood Adv. (2017) 1:1274-86. doi: 10.1182/bloodadvances.2017006163

40. Schaale K, Brandenburg J, Kispert A, Leitges M, Ehlers S, Reiling N. Wnt6 is expressed in granulomatous lesions of Mycobacterium tuberculosis-infected mice and is involved in macrophage differentiation and proliferation. $J$ Immunol. (2013) 191:5182-95. doi: 10.4049/jimmunol.1201819

41. Neumann J, Schaale K, Farhat K, Endermann T, Ulmer AJ, Ehlers S, et al. Frizzled 1 is a marker of inflammatory macrophages, and its ligand Wnt3a is involved in reprogramming Mycobacterium tuberculosis-infected macrophages. FASEB J. (2010) 24:4599-612. doi: 10.1096/fj.10-160994

42. Luo T, Dunphy PS, Lina TT, McBride JW. Ehrlichia chaffeensis exploits canonical and noncanonical host wnt signaling pathways to stimulate phagocytosis and promote intracellular survival. Infect Immun. (2015) 84:686-700. doi: 10.1128/IAI.01289-15

43. Liu X, Lu R, Wu S, Sun J. Salmonella regulation of intestinal stem cells through the Wnt/beta-catenin pathway. FEBS Lett. (2010) 584:911-6. doi: 10.1016/j.febslet.2010.01.024
44. Bansal K, Trinath J, Chakravortty D, Patil SA, Balaji KN. Pathogen-specific TLR2 protein activation programs macrophages to induce Wnt-beta-catenin signaling. J Biol Chem. (2011) 286:37032-44. doi: 10.1074/jbc.M111.260414

45. Labed SA, Wani KA, Jagadeesan S, Hakkim A, Najibi M, Irazoqui JE. Intestinal epithelial Wnt signaling mediates acetylcholine-triggered host defense against infection. Immunity. (2018) 48:963-978.e3. doi: 10.1016/j.immuni.2018.04.017

46. Du J, Zhang X, Yuan J, Zhang X, Li F, Xiang J. Wnt gene family members and their expression profiling in Litopenaeus vannamei. Fish Shellfish Immunol. (2018). 77:233-43. doi: 10.1016/j.fsi.2018.03.034

47. Wang J, Lu R, Fu X, Dan Z, Zhang YG, Chang X, et al. Novel regulatory roles of wnt1 in infection-associated colorectal cancer. Neoplasia. (2018) 20:499-509. doi: 10.1016/j.neo.2018.03.001

48. Zhao W, Sun Z, Wang S, Li Z, Zheng L. Wntl participates in inflammation induced by lipopolysaccharide through upregulating scavenger receptor $\mathrm{A}$ and NF-kB. Inflammation. (2015) 38:1700-6. doi: 10.1007/s10753-015-0147-8

49. Kuypers E, Willems MG, Collins JJ, Wolfs TG, Nitsos I, Jane Pillow J, et al. Altered canonical Wingless-Int signaling in the ovine fetal lung after exposure to intra-amniotic lipopolysaccharide and antenatal betamethasone. Pediatr Res. (2014) 75:281-7. doi: 10.1038/pr.2013.226

50. Liu X, Lu R, Wu S, Zhang YG, Xia Y, Sartor RB, et al. Wnt2 inhibits enteric bacterial-induced inflammation in intestinal epithelial cells. Inflamm Bowel Dis. (2012) 18:418-29. doi: 10.1002/ibd.21788

51. Kim GL, Lee S, Kim SJ, Lee SO, Pyo S, Rhee DK. Pulmonary colonization resistance to pathogens via noncanonical Wnt and interleukin-17A by Intranasal pep27 mutant immunization. J Infect Dis. (2018) 217:1977-86. doi: 10.1093/infdis/jiy158

52. Loilome W, Bungkanjana $P$, Techasen A, Namwat $N$, Yongvanit $P$, Puapairoj A, et al. Activated macrophages promote Wnt $\beta$-catenin signaling in cholangiocarcinoma cells. Tumour Biol. (2014) 35:5357-67. doi: 10.1007/s13277-014-1698-2

53. Jang J, Jung Y, Kim Y, Jho EH, Yoon Y. LPS-induced inflammatory response is suppressed by Wnt inhibitors, Dickkopf-1 and LGK974. Sci Rep. (2017) 7:41612. doi: 10.1038/srep41612

54. van der Sar AM, Spaink HP, Zakrzewska A, Bitter W, Meijer AH. Specificity of the zebrafish host transcriptome response to acute and chronic mycobacterial infection and the role of innate and adaptive immune components. Mol Immunol. (2009) 46:2317-32. doi: 10.1016/j.molimm.2009.03.024

55. Di Cara F, Sheshachalam A, Braverman NE, Rachubinski RA, Simmonds AJ. Peroxisome-mediated metabolism is required for immune response to microbial infection. Immunity. (2017) 47:93-106.e7. doi: 10.1016/j.immuni.2017.06.016

56. Liu X, Wu S, Xia Y, Li XE, Xia Y, Zhou ZD, et al. Wingless homolog Wnt11 suppresses bacterial invasion and inflammation in intestinal epithelial cells. Am J Physiol Gastrointest Liver Physiol. (2011). 301:G992-1003. doi: 10.1152/ajpgi.00080.2011

57. Jati S, Kundu S, Chakraborty A, Mahata SK, Nizet V, Sen M. Wnt5A signaling promotes defense against bacterial pathogens by activating a host autophagy circuit. Front Immunol. (2018). 9:679. doi: 10.3389/fimmu.2018.00679

58. Mysorekar IU, Mulvey MA, Hultgren SJ, Gordon JI. Molecular regulation of urothelial renewal and host defenses during infection with uropathogenic Escherichia coli. J Biol Chem. (2002) 277:7412-9. doi: 10.1074/jbc.M110560200

59. Ting K, Aitken KJ, Penna F, Samiei AN, Sidler M, Jiang JX, et al. Uropathogenic E. coli (UPEC) infection induces proliferation through enhancer of zeste homologue 2 (EZH2). PLoS ONE. (2016). 11:e0149118. doi: 10.1371/journal.pone.0149118

60. Nanbara H, Wara-aswapati N, Nagasawa T, Yoshida Y, Yashiro R, Bando Y, et al. Modulation of Wnt5a expression by periodontopathic bacteria. PLoS ONE. (2012). 7:e34434. doi: 10.1371/journal.pone.0034434

61. Mehmeti M, Bergenfelz C, Kallberg E, Millrud CR, Bjork P, Ivars $\mathrm{F}$, et al. Wnt5a is a TLR2/4-ligand that induces tolerance in human myeloid cells. Commun Biol. (2019). 2:176. doi: 10.1038/s42003-0190432-4 
62. Hoogendijk AJ, Diks SH, van der Poll T, Peppelenbosch MP, Wieland CW. Kinase activity profiling of pneumococcal pneumonia. PLoS ONE. (2011). 6:e18519. doi: 10.1371/journal.pone.0018519

63. Fu Q, Chen K, Zhu Q, Wang W, Huang F, Miao L, et al. $\beta$-catenin promotes intracellular bacterial killing via suppression of Pseudomonas aeruginosa-triggered macrophage autophagy. J Int Med Res. (2017) 45:55669. doi: $10.1177 / 0300060517692147$

64. Duan Y, Liao AP, Kuppireddi S, Ye Z, Ciancio MJ, Sun J. beta-Catenin activity negatively regulates bacteria-induced inflammation. Lab Invest. (2007) 87:613-24. doi: 10.1038/labinvest.3700545

65. Sun J, Hobert ME, Rao AS, Neish AS, Madara JL. Bacterial activation of betacatenin signaling in human epithelia. Am J Physiol Gastrointest Liver Physiol. (2004). 287:G220-7. doi: 10.1152/ajpgi.00498.2003

66. Ye Z, Petrof EO, Boone D, Claud EC, Sun J. Salmonella effector AvrA regulation of colonic epithelial cell inflammation by deubiquitination. Am J Pathol. (2007) 171:882-92. doi: 10.2353/ajpath.2007.070220

67. Liao AP, Petrof EO, Kuppireddi S, Zhao Y, Xia Y, Claud EC, et al. Salmonella type III effector AvrA stabilizes cell tight junctions to inhibit inflammation in intestinal epithelial cells. PLoS ONE. (2008). 3:e2369. doi: 10.1371/journal.pone.0002369

68. Schulte DM, Kragelund D, Muller N, Hagen I, Elke G, Titz A, et al. The wingless-related integration site-5a/secreted frizzled-related protein-5 system is dysregulated in human sepsis. Clin Exp Immunol. (2015) 180:90-7. doi: $10.1111 /$ cei.12484

69. Villar J, Cabrera-Benitez NE, Ramos-Nuez A, Flores C, Garcia-Hernandez S, Valladares F, et al. Early activation of pro-fibrotic WNT5A in sepsis-induced acute lung injury. Crit Care. (2014). 18:568. doi: 10.1186/s13054-014-0568-Z

70. Fukutomi T, Zhou Y, Kawai S, Eguchi H, Wands JR, Li J. Hepatitis C virus core protein stimulates hepatocyte growth: correlation with upregulation of wnt-1 expression. Hepatology. (2005) 41:1096-105. doi: 10.1002/hep.20668

71. Richards MH, Narasipura SD, Kim S, Seaton MS, Lutgen V, Al-Harthi L. Dynamic interaction between astrocytes and infiltrating PBMCs in context of neuro AIDS. Glia. (2015) 63:441-51. doi: 10.1002/glia.22763

72. Forero A, Tisoncik-Go J, Watanabe T, Zhong G, Hatta M, Tchitchek N, et al. The 1918 influenza virus PB2 protein enhances virulence through the disruption of inflammatory and Wnt-mediated signaling in mice. $J$ Virol. (2015) 90:2240-53. doi: 10.1128/JVI.02974-15

73. Li Q, Yu P, Wang W, Zhang P, Yang H, Li S, et al. Gene expression profiles of various cytokines in mesenchymal stem cells derived from umbilical cord tissue and bone marrow following infection with human cytomegalovirus. Cell Mol Biol Lett. (2014) 19:140-57. doi: 10.2478/s11658-014-0187-3

74. Volpini X, Ambrosio LF, Fozzatti L, Insfran C, Stempin CC, Cervi L, Motran CC. Trypanosoma cruzi exploits Wnt signaling pathway to promote its intracellular replication in macrophages. Front Immunol. (2018). 9:859. doi: 10.3389/fimmu.2018.00859

75. Yap LF, Ahmad M, Zabidi MM, Chu TL, Chai SJ, Lee HM, et al. Oncogenic effects of WNT5A in Epstein-Barr virusassociated nasopharyngeal carcinoma. Int J Oncol. (2014) 44:1774-80. doi: 10.3892/ijo.2014.2342

76. Kapoor A, He R, Venkatadri R, Forman M, Arav-Boger R. Wnt modulating agents inhibit human cytomegalovirus replication. Antimicrob Agents Chemother. (2013) 57:2761-7. doi: 10.1128/AAC.00029-13

77. Li B, Shi Y, Shu J, Gao J, Wu P, Tang SJ. Wingless-type mammary tumor virus integration site family, member 5A (Wnt5a) regulates human immunodeficiency virus type 1 (HIV-1) envelope glycoprotein 120 (gp120)-induced expression of pro-inflammatory cytokines via the $\mathrm{Ca} 2+/$ calmodulin-dependent protein kinase II (CaMKII) and c-Jun Nterminal kinase (JNK) signaling pathways. J Biol Chem. (2013) 288:13610-9. doi: 10.1074/jbc.M112.381046

78. Che C, Li C, Lin J, Zhang J, Jiang N, Yuan K, et al. Wnt5a contributes to dectin-1 and LOX-1 induced host inflammatory response signature in Aspergillus fumigatus keratitis. Cell Signal. (2018). 52:103-11. doi: 10.1016/j.cellsig.2018.08.020

79. Trinath J, Holla S, Mahadik K, Prakhar P, Singh V, Balaji KN. The WNT signaling pathway contributes to dectin-1-dependent inhibition of toll-like receptor-induced inflammatory signature. Mol Cell Biol. (2014) 34:4301-14. doi: 10.1128/MCB.00641-14

80. Chakraborty A, Kurati SP, Mahata SK, Sundar S, Roy S, Sen M. Wnt5a Signaling promotes host defense against Leishmania donovani infection. J Immunol. (2017) 199:992-1002. doi: 10.4049/jimmunol.16 01927

81. Fragoso-Ontiveros V, Maria Alvarez-Garcia R, Contreras-Paredes A, VacaPaniagua F, Alonso Herrera L, Lopez-Camarillo C, et al. Gene expression profiles induced by E6 from non-European HPV18 variants reveals a differential activation on cellular processes driving to carcinogenesis. Virology. (2012) 432:81-90. doi: 10.1016/j.virol.2012.05.029

82. Harmon B, Bird SW, Schudel BR, Hatch AV, Rasley A, Negrete OA. A Genome-wide RNA interference screen identifies a role for Wnt/ $\beta$-catenin signaling during rift valley fever virus infection. J Virol. (2016) 90:7084-97. doi: 10.1128/JVI.00543-16

83. Angelova M, Zwezdaryk K, Ferris M, Shan B, Morris CA, Sullivan DE. Human cytomegalovirus infection dysregulates the canonical Wnt/ß-catenin signaling pathway. PLoS Pathog. (2012). 8:e1002959. doi: 10.1371/journal.ppat.1002959

84. Hsieh A, Kim HS, Lim SO, Yu DY, Jung G. Hepatitis B viral X protein interacts with tumor suppressor adenomatous polyposis coli to activate Wnt/ $\beta$-catenin signaling. Cancer Lett. (2011) 300:162-72. doi: $10.1016 /$ j.canlet.2010.09.018

85. Liu J, Ding X, Tang J, Cao Y, Hu P, Zhou F, et al. Enhancement of canonical Wnt/ $\beta$-catenin signaling activity by HCV core protein promotes cell growth of hepatocellular carcinoma cells. PLoS ONE. (2011). 6:e27496. doi: 10.1371/journal.pone.0027496

86. Jang KL, Shackelford J, Seo SY, Pagano JS. Up-regulation of beta-catenin by a viral oncogene correlates with inhibition of the seven in absentia homolog 1 in B lymphoma cells. Proc Natl Acad Sci USA. (2005) 102:18431-6. doi: 10.1073/pnas.0504054102

87. Maluquer de Motes C, Smith GL. Vaccinia virus protein A49 activates Wnt signalling by targetting the E3 ligase beta-TrCP. J Gen Virol. (2017) 98:3086-92. doi: 10.1099/jgv.0.000946

88. Gordon MD, Dionne MS, Schneider DS, Nusse R. WntD is a feedback inhibitor of Dorsal/NF-kappaB in Drosophila development and immunity. Nature. (2005) 437:746-9. doi: 10.1038/nature04073

89. Papapietro O, Teatero S, Thanabalasuriar A, Yuki KE, Diez E, Zhu L, et al. $\mathrm{R}$-spondin 2 signalling mediates susceptibility to fatal infectious diarrhoea. Nat Commun. (2013). 4:1898. doi: 10.1038/nrmicro2053

90. Hu X, Zhou J, Chen X, Zhou Y, Song X, Cai B, et al. Pathway analyses identify novel variants in the WNT signaling pathway associated with tuberculosis in Chinese population. Sci Rep. (2016). 6:28530. doi: 10.1038/srep28530

91. Zhao Z, Peng W, Hu X, Zhang J, Shang M, Zhou J, et al. SFRP1 variations influence susceptibility and immune response to Mycobacterium tuberculosis in a Chinese Han population. Infect Genet Evol. (2016). 37:25965. doi: 10.1016/j.meegid.2015.11.031

92. Liu Y, El-Serag HB, Jiao L, Lee J, Moore D, Franco LM, et al. WNT signaling pathway gene polymorphisms and risk of hepatic fibrosis and inflammation in HCV-infected patients. PLOS ONE. (2013). 8:e84407. doi: 10.1371/journal.pone.0084407

93. Huang H, Fujii H, Sankila A, Mahler-Araujo BM, Matsuda M, Cathomas $\mathrm{G}$, et al. Beta-catenin mutations are frequent in human hepatocellular carcinomas associated with hepatitis C virus infection. Am J Pathol. (1999) 155:1795-801. doi: 10.1016/S0002-9440(10)65496-X

94. Suryawanshi A, Manoharan I, Hong Y, Swafford D, Majumdar T, Taketo MM, et al. Manicassamy S, Canonical wnt signaling in dendritic cells regulates Th1/Th17 responses and suppresses autoimmune neuroinflammation. J Immunol. (2015) 194:3295-304. doi: 10.4049/jimmunol. 1402691

95. Manicassamy S, Reizis B, Ravindran R, Nakaya H, Salazar-Gonzalez RM, Wang YC, et al.Activation of beta-catenin in dendritic cells regulates immunity versus tolerance in the intestine. Science. (2010) 329:849-53. doi: $10.1126 /$ science. 1188510

96. Zhu F, Zhang $\mathrm{X}$. The Wnt signaling pathway is involved in the regulation of phagocytosis of virus in Drosophila. Sci Rep. (2013) 3:2069. doi: $10.1038 /$ srep02069

97. Baril M, Es-Saad S, Chatel-Chaix L, Fink K, Pham T, Raymond VA, et al. Genome-wide RNAi screen reveals a new role of a WNT/CTNNB1 signaling pathway as negative regulator of virus-induced innate immune responses. PLoS Pathog. (2013). 9:e1003416. doi: 10.1371/journal.ppat.10 03416 
98. Maiti G, Naskar D, Sen M. The Wingless homolog Wnt5a stimulates phagocytosis but not bacterial killing. Proc Natl Acad Sci USA. (2012) 109:16600-5. doi: 10.1073/pnas.1207789109

99. Wu X, Zhang J, Ma C, Li W, Zeng J, Wang Y, et al. A role for Wnt/ $\beta$-catenin signalling in suppressing Bacillus Calmette-Guerininduced macrophage autophagy. Microb Pathog. (2019). 127:277-87. doi: 10.1016/j.micpath.2018.12.016

100. Chen K, Fu Q, Li D, Wu Y, Sun S, Zhang X. Wnt3a suppresses Pseudomonas aeruginosa-induced inflammation and promotes bacterial killing in macrophages. Mol Med Rep. (2016) 13:2439-46. doi: $10.3892 / \mathrm{mmr} .2016 .4869$

101. Vikram A, Kim YR, Kumar S, Naqvi A, Hoffman TA, Kumar A, et al. Canonical Wnt signaling induces vascular endothelial dysfunction via p66Shc-regulated reactive oxygen species. Arterioscler Thromb Vasc Biol. (2014) 34:2301-9. doi: 10.1161/ATVBAHA.114.304338

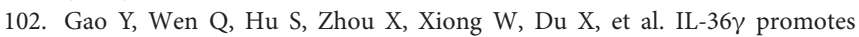
killing of Mycobacterium tuberculosis by macrophages via WNT5Ainduced noncanonical WNT signaling. I Immunol. (2019) 203:922-35. doi: 10.4049/jimmunol.1900169

103. Holla S, Kurowska-Stolarska M, Bayry J, Balaji KN. Selective inhibition of IFNG-induced autophagy by Mir155- and Mir31-responsive WNT5A and SHH signaling. Autophagy. (2014) 10:311-30. doi: 10.4161/auto.27225

104. Naskar D, Maiti G, Chakraborty A, Roy A, Chattopadhyay D, Sen M. Wnt5a-Rac1-NF-kappaB homeostatic circuitry sustains innate immune functions in macrophages. J Immunol. (2014) 192:4386-97. doi: $10.4049 /$ jimmunol.1302817

105. Bergenfelz C, Medrek C, Ekstrom E, Jirstrom K, Janols H, Wullt $\mathrm{M}$, et al. Wnt5a induces a tolerogenic phenotype of macrophages in sepsis and breast cancer patients. J Immunol. (2012) 188:5448-58. doi: 10.4049/jimmunol.1103378

106. Wallace J, Lutgen V, Avasarala S, St Croix B, Winn RA, Al-Harthi L. Wnt7a induces a unique phenotype of monocyte-derived macrophages with lower phagocytic capacity and differential expression of proand anti-inflammatory cytokines. Immunology. (2018) 153:203-213. doi: $10.1111 / \mathrm{imm} .12830$

107. Aoukaty A, Tan R. Role for glycogen synthase kinase-3 in NK cell cytotoxicity and X-linked lymphoproliferative disease. J Immunol. (2005) 174:4551-8. doi: 10.4049/jimmunol.174.8.4551

108. Deng ZB, Zhuang X, Ju S, Xiang X, Mu J, Wang Q, et al. Intestinal mucusderived nanoparticle-mediated activation of $\mathrm{Wnt} / \beta$-catenin signaling plays a role in induction of liver natural killer $\mathrm{T}$ cell anergy in mice. Hepatology. (2013) 57:1250-61. doi: 10.1002/hep.26086

109. Carr T, Krishnamoorthy V, Yu S, Xue HH, Kee BL, Verykokakis M. The transcription factor lymphoid enhancer factor 1 controls invariant natural killer $\mathrm{T}$ cell expansion and Th2-type effector differentiation. J Exp Med. (2015) 212:793-807. doi: 10.1084/jem.20141849

110. Kling JC, Blumenthal A. Roles of WNT, NOTCH, Hedgehog signaling in the differentiation and function of innate and innate-like lymphocytes. J Leukoc Biol. (2017) 101:827-40. doi: 10.1189/jlb.1MR0616-272R

111. van Loosdregt $\mathrm{J}$, Coffer PJ. The role of WNT signaling in mature $\mathrm{T}$ cells: T cell factor is coming home. J Immunol. (2018) 201:2193-2200. doi: 10.4049/jimmunol.1800633

112. Kling JC, Jordan MA, Pitt LA, Meiners J, Thanh-Tran T, Tran LS, et al. Temporal regulation of natural killer $\mathrm{T}$ cell interferon gamma responses by beta-catenin-dependent and -independent Wnt signaling. Front Immunol. (2018). 9:483. doi: 10.3389/fimmu.2018.00483

113. Sato A, Kayama H, Shojima K, Matsumoto S, Koyama H, Minami Y, et al. The Wnt5a-Ror2 axis promotes the signaling circuit between interleukin-12 and interferon-gamma in colitis. Sci Rep. (2015). 5:10536. doi: 10.1038/srep 10536

114. Shapira SD, Gat-Viks I, Shum BO, Dricot A, de Grace MM, Wu L, et al. A physical and regulatory map of host-influenza interactions reveals pathways in H1N1 infection. Cell. (2009) 139:1255-67. doi: 10.1016/j.cell.2009. 12.018

115. Mohammadpour H, Pourfathollah AA, Nikougoftar Zarif M, Tahoori MT. Effects of DKK-3, a Wnt signaling inhibitor, on dendritic cell phenotype and T cell polarization. Immunopharmacol Immunotoxicol. (2015) 37:481-7. doi: $10.3109 / 08923973.2015 .1089274$
116. Fuerer C, Nusse R. Lentiviral vectors to probe and manipulate the Wnt signaling pathway. PLoS ONE. (2010). 5:e9370. doi: 10.1371/journal.pone.0009370

117. Yu CH, Nguyen TT, Irvine KM, Sweet MJ, Frazer IH, Blumenthal A. Recombinant Wnt3a and Wnt5a elicit macrophage cytokine production and tolerization to microbial stimulation via Toll-like receptor 4. Eur J Immunol. (2014) 44:1480-90. doi: 10.1002/eji.201343959

118. Irvine KM, Clouston AD, Gadd VL, Miller GC, Wong WY, Melino M, et al. Deletion of Wntless in myeloid cells exacerbates liver fibrosis and the ductular reaction in chronic liver injury. Fibrogenesis Tissue Repair. (2015) 8:19. doi: 10.1186/s13069-015-0036-7

119. Sharma A, Yang WL, Ochani M, Wang P. Mitigation of sepsis-induced inflammatory responses and organ injury through targeting Wnt/ $\beta$-catenin signaling. Sci Rep. (2017). 7:9235. doi: 10.1038/s41598-017-08711-6

120. Suryawanshi A, Tadagavadi RK, Swafford D, Manicassamy S. Modulation of inflammatory responses by $\mathrm{Wnt} / \beta$-catenin signaling in dendritic cells: a novel immunotherapy target for autoimmunity and cancer. Front Immunol. (2016). 7:460. doi: 10.3389/fimmu.2016.00460

121. Monga SP. Role and regulation of beta-catenin signaling during physiological liver growth. Gene Expr. (2014) 16:51-62. doi: $10.3727 / 105221614 \mathrm{X} 13919976902138$

122. Valenta T, Hausmann G, Basler K. The many faces and functions of betacatenin. EMBO J. (2012) 31:2714-36. doi: 10.1038/emboj.2012.150

123. Chen B, Dodge ME, Tang W, Lu J, Ma Z, Fan CW, et al.. Small moleculemediated disruption of Wnt-dependent signaling in tissue regeneration and cancer. Nat Chem Biol. (2009) 5:100-7. doi: 10.1038/nchembio.137

124. Rikihisa Y. Anaplasma phagocytophilum and Ehrlichia chaffeensis: subversive manipulators of host cells. Nat Rev Microbiol. (2010) 8:328-39. doi: 10.1038/nrmicro2318

125. Luo T, Kuriakose JA, Zhu B, Wakeel A, McBride JW. Ehrlichia chaffeensis TRP120 interacts with a diverse array of eukaryotic proteins involved in transcription, signaling, and cytoskeleton organization. Infect Immun. (2011) 79:4382-91. doi: 10.1128/IAI.05608-11

126. Zhu B, Kuriakose JA, Luo T, Ballesteros E, Gupta S, Fofanov Y, McBride JW. Ehrlichia chaffeensis TRP120 binds a G+C-rich motif in host cell DNA and exhibits eukaryotic transcriptional activator function. Infect Immun. (2011) 79:4370-81. doi: 10.1128/IAI.05422-11

127. Ogawa M, Matsuda R, Takada N, Tomokiyo M, Yamamoto S, Shizukusihi $\mathrm{S}$, et al. Molecular mechanisms of Streptococcus pneumoniae-targeted autophagy via pneumolysin, Golgi-resident Rab41, and Nedd4-1mediated K63-linked ubiquitination. Cell Microbiol. (2018). 20:e12846. doi: $10.1111 / \mathrm{cmi} .12846$

128. Li X, He S, Zhou X, Ye Y, Tan S, Zhang S, et al. Lyn Delivers Bacteria to Lysosomes for Eradication through TLR2-Initiated Autophagy Related Phagocytosis. PLoS Pathog. (2016). 12:e1005363. doi: 10.1371/journal.ppat.1005363

129. Deng Q, Wang Y, Zhang Y, Li M, Li D, Huang X, et al. Pseudomonas aeruginosa triggers macrophage autophagy to escape intracellular killing by activation of the NLRP3 inflammasome. Infect Immun. (2016) 84:56-66. doi: 10.1128/IAI.00945-15

130. Yuan K, Huang C, Fox J, Laturnus D, Carlson E, Zhang B, et al. Autophagy plays an essential role in the clearance of Pseudomonas aeruginosa by alveolar macrophages. J Cell Sci. (2012). 125:507-15. doi: 10.1242/jcs.094573

131. Wu Y, Li D, Wang Y, Chen K, Yang K, Huang X, et al. Pseudomonas aeruginosa promotes autophagy to suppress macrophage-mediated bacterial eradication. Int Immunopharmacol. (2016). 38:214-22. doi: 10.1016/j.intimp.2016.04.044

132. Lina TT, Luo T, Velayutham TS, Das S, McBride JW. Ehrlichia activation of Wnt-PI3K-mTOR signaling inhibits autolysosome generation and autophagic destruction by the mononuclear phagocyte. Infect Immun. (2017). 85:e00690-17. doi: 10.1128/IAI.00690-17

133. Gao C, Cao W, Bao L, Zuo W, Xie G, Cai T, et al. Autophagy negatively regulates Wnt signalling by promoting Dishevelled degradation. Nat Cell Biol. (2010) 12:781-90. doi: 10.1038/ncb2082

134. Jia Z, Wang J, Wang W, Tian Y, Xiang Wei W, Chen P, et al. Autophagy eliminates cytoplasmic beta-catenin and NICD to promote the cardiac differentiation of P19CL6 cells. Cell Signal. (2014) 26:2299-305. doi: $10.1016 /$ j.cellsig.2014.07.028 
135. Yang Z, Zhao T, Liu H, Zhang L. Ginsenoside Rh2 inhibits hepatocellular carcinoma through beta-catenin and autophagy. Sci Rep. (2016). 6:19383. doi: 10.1038/srep19383

136. Kim JS, Yeo S, Shin DG, Bae YS, Lee JJ, Chin BR, et al. Glycogen synthase kinase 3 beta and beta-catenin pathway is involved in toll-like receptor 4mediated NADPH oxidase 1 expression in macrophages. FEBS J. (2010) 277:2830-7. doi: 10.1111/j.1742-4658.2010.07700.x

137. Jiang A, Okabe H, Popovic B, Preziosi ME, Pradhan-Sundd T, Poddar M, et al. Loss of Wnt secretion by macrophages promotes hepatobiliary injury after administration of 3,5-diethoxycarbonyl-1, 4-dihydrocollidine diet. Am J Pathol. (2019) 189:590-603. doi: 10.1016/j.ajpath.2018.11.010

138. Palevski D, Levin-Kotler LP, Kain D, Naftali-Shani N, Landa N, BenMordechai T, et al. Loss of macrophage Wnt secretion improves remodeling and function after myocardial infarction in mice. J Am Heart Assoc. (2017) 6:e004387. doi: 10.1161/JAHA.116.004387

139. Du Q, Park KS, Guo Z, He P, Nagashima M, Shao L, et al. Regulation of human nitric oxide synthase 2 expression by Wnt beta-catenin signaling. Cancer Res. (2006) 66:7024-31. doi: 10.1158/0008-5472.CAN-05-4110

140. van Es JH, Jay P, Gregorieff A, van Gijn ME, Jonkheer S, Hatzis P, et al. Wnt signalling induces maturation of Paneth cells in intestinal crypts. Nat Cell Biol. (2005) 7:381-6. doi: 10.1038/ncb1240

141. Wu $\mathrm{H}$, Gong J, Liu Y. Indoleamine 2, 3-dioxygenase regulation of immune response (Review). Mol Med Rep. (2018) 17:4867-73. doi: 10.3892/mmr.2018.8537

142. Knubel CP, Martinez FF, Acosta Rodriguez EV, Altamirano A, Rivarola HW, Diaz Lujan C, et al. 3-Hydroxy kynurenine treatment controls $T$. cruzi replication and the inflammatory pathology preventing the clinical symptoms of chronic Chagas disease. PLoS ONE. (2011). 6:e26550. doi: 10.1371/journal.pone.0026550

143. Knubel CP, Martinez FF, Fretes RE, Diaz Lujan C, Theumer MG, Cervi L, et al. Indoleamine 2,3-dioxigenase (IDO) is critical for host resistance against Trypanosoma cruzi. FASEB J. (2010) 24:2689-701. doi: 10.1096/fj.09-150920

144. Swafford D, Shanmugam A, Ranganathan P, Hussein MS, Koni PA, Prasad $\mathrm{PD}$, et al. Canonical Wnt signaling in $\mathrm{CD} 11 \mathrm{c}(+)$ APCs regulates microbiotainduced inflammation and immune cell homeostasis in the colon. J Immunol. (2018) 200:3259-68. doi: 10.4049/jimmunol.1701086

145. Zhao F, Xiao C, Evans KS, Theivanthiran T, DeVito N, Holtzhausen A, et al. Paracrine Wnt5a- $\beta$-catenin signaling triggers a metabolic program that drives dendritic cell tolerization. Immunity. (2018) 48:147-60.e7. doi: 10.1016/j.immuni.2017.12.004

146. Yang P, An H, Liu X, Wen M, Zheng Y, Rui Y, et al. The cytosolic nucleic acid sensor LRRFIP1 mediates the production of type I interferon via a beta-catenin-dependent pathway. Nat Immunol. (2010) 11:487-94. doi: $10.1038 /$ ni. 1876

147. Hillesheim A, Nordhoff C, Boergeling Y, Ludwig S, Wixler V. $\beta$-catenin promotes the type I IFN synthesis and the IFN-dependent signaling response but is suppressed by influenza A virus-induced RIG-I/NF-kappaB signaling. Cell Commun Signal. (2014). 12:29. doi: 10.1186/1478-811X-12-29

148. Wang JT, Chang LS, Chen CJ, Doong SL, Chang CW, Chen MR. Glycogen synthase kinase 3 negatively regulates IFN regulatory factor 3 transactivation through phosphorylation at its linker region. Innate Immun. (2014) 20:7887. doi: $10.1177 / 1753425913485307$

149. Lei CQ, Zhong B, Zhang Y, Zhang J, Wang S, Shu HB. Glycogen synthase kinase $3 \beta$ regulates IRF3 transcription factor-mediated antiviral response via activation of the kinase TBK1. Immunity. (2010) 33:878-89. doi: 10.1016/j.immuni.2010.11.021

150. Khan KA, Do F, Marineau A, Doyon P, Clement JF, Woodgett JR, et al. Fine-Tuning of the RIG-I-like receptor/interferon regulatory factor 3-dependent antiviral innate immune response by the glycogen synthase kinase 3/ $\beta$-catenin pathway. Mol Cell Biol. (2015) 35:3029-43. doi: 10.1128/MCB.00344-15

151. Zhu J, Coyne CB, Sarkar SN. PKC alpha regulates Sendai virus-mediated interferon induction through HDAC6 and beta-catenin. EMBO J. (2011) 30:4838-49. doi: 10.1038/emboj.2011.351

152. Marcato V, Luron L, Laqueuvre LM, Simon D, Mansuroglu Z, Flamand $\mathrm{M}$, et al. $\beta$-catenin upregulates the constitutive and virus-induced transcriptional capacity of the interferon beta promoter through T-cell factor binding sites. Mol Cell Biol. (2016) 36:13-29. doi: 10.1128/MCB.00641-15
153. Smith JL, Jeng S, McWeeney SK, Hirsch AJ. A MicroRNA screen identifies the Wnt signaling pathway as a regulator of the interferon response during flavivirus infection. J Virol. (2017). 91:e02388-16. doi: 10.1128/JVI.02388-16

154. Hancock AS, Stairiker CJ, Boesteanu AC, Monzon-Casanova E, Lukasiak S, Mueller YM, et al. Transcriptome analysis of infected and bystander type 2 alveolar epithelial cells during influenza A virus infection reveals in vivo Wnt pathway downregulation. J Virol. (2018). 92:e01325-18. doi: 10.1128/JVI.01325-18

155. Villasenor T, Madrid-Paulino E, Maldonado-Bravo R, Urban-Aragon A, Perez-Martinez L, Pedraza-Alva G. Activation of the Wnt pathway by Mycobacterium tuberculosis: a Wnt-Wnt situation. Front Immunol. (2017) 8:50. doi: 10.3389/fimmu.2017.00050

156. Brandenburg J, Reiling N. The Wnt blows: on the functional role of Wnt signaling in Mycobacterium tuberculosis infection and beyond. Front Immunol. (2016) 7:635. doi: 10.3389/fimmu.2016.00635

157. Shao Y, Zheng Q, Wang W, Xin N, Song X, Zhao C. Biological functions of macrophage-derived Wnt5a, its roles in human diseases. Oncotarget. (2016) 7:67674-67684. doi: 10.18632/oncotarget.11874

158. Silva-Garcia O, Valdez-Alarcon JJ, Baizabal-Aguirre VM. The Wnt/ $\beta$ catenin signaling pathway controls the inflammatory response in infections caused by pathogenic bacteria. Mediators Inflamm. (2014). 2014:310183. doi: $10.1155 / 2014 / 310183$

159. George SJ. Wnt pathway: a new role in regulation of inflammation. Arterioscler Thromb Vasc Biol. (2008) 28:400-2. doi: 10.1161/ATVBAHA.107.160952

160. van Zuylen WJ, Rawlinson WD, Ford CE. The Wnt pathway: a key network in cell signalling dysregulated by viruses. Rev Med Virol. (2016) 26:340-55. doi: $10.1002 / \mathrm{rmv} .1892$

161. Schaale K, Neumann J, Schneider D, Ehlers S, Reiling N. Wnt signaling in macrophages: augmenting and inhibiting mycobacteriainduced inflammatory responses. Eur J Cell Biol. (2011) 90:553-9. doi: 10.1016/j.ejcb.2010.11.004

162. Swafford D, Manicassamy S. Wnt signaling in dendritic cells: its role in regulation of immunity and tolerance. Discov Med. (2015) 19:303-10.

163. Bhatt PM, Malgor R. Wnt5a: a player in the pathogenesis of atherosclerosis and other inflammatory disorders. Atherosclerosis. (2014) 237:155-62. doi: 10.1016/j.atherosclerosis.2014.08.027

164. Lehoczky JA, Tabin CJ. Rethinking WNT signalling. Nature. (2018) 557:4956. doi: 10.1038/d41586-018-04820-y

165. Jiang $\mathrm{X}$, Cong F. Novel regulation of Wnt signaling at the proximal membrane level. Trends Biochem Sci. (2016) 41:773-783. doi: 10.1016/j.tibs.2016.06.003

166. Sen M, Chamorro M, Reifert J, Corr M, Carson DA. Blockade of Wnt5A/frizzled 5 signaling inhibits rheumatoid synoviocyte activation. Arthritis Rheum. (2001) 44:772-81. doi: 10.1002/1529-0131(200104)44:4<772::AIDANR133>3.0.CO;2-L

167. Rauner M, Stein N, Winzer M, Goettsch C, Zwerina J, Schett G, et al. WNT5A is induced by inflammatory mediators in bone marrow stromal cells and regulates cytokine and chemokine production. J Bone Miner Res. (2012) 27:575-85. doi: 10.1002/jbmr.1488

168. Holtzhausen A, Zhao F, Evans KS, Tsutsui M, Orabona C, Tyler DS, et al. Melanoma-derived Wnt5a promotes local dendritic-cell expression of IDO and immunotolerance: opportunities for pharmacologic enhancement of immunotherapy. Cancer Immunol Res. (2015) 3:1082-95. doi: 10.1158/2326-6066.CIR-14-0167

169. Zhang Y, Pizzute T, Pei M. A review of crosstalk between MAPK and Wnt signals and its impact on cartilage regeneration. Cell Tissue Res. (2014) 358:633-49. doi: 10.1007/s00441-014-2010-x

170. Du Q, Geller DA. Cross-regulation between Wnt and NF-кB signaling pathways. For Immunopathol Dis Therap. (2010) 1:155-81.

171. Murray PJ. Macrophage polarization. Annu Rev Physiol. (2017). 79:541-66. doi: 10.1146/annurev-physiol-022516-034339

172. Murray PJ, Rathmell J, Pearce E. SnapShot: immunometabolism. Cell Metab. (2015) 22:190.e1. doi: 10.1016/j.cmet.2015.06.014

173. Chen D, Li G, Fu X, Li P, Zhang J, Luo L. Wnt5a deficiency regulates inflammatory cytokine secretion, polarization, and apoptosis in Mycobacterium tuberculosis-infected macrophages. DNA Cell Biol. (2017) 36:58-66. doi: 10.1089/dna.2016.3418 
174. Valencia J, Martinez VG, Hidalgo L, Hernandez-Lopez C, Canseco NM, Vicente A, et al. Wnt5a signaling increases IL-12 secretion by human dendritic cells and enhances IFN- $\gamma$ production by CD4+ $\mathrm{T}$ cells. Immunol Lett. (2014). 162:188-99. doi: 10.1016/j.imlet.2014. 08.015

175. Valencia J, Hernandez-Lopez C, Martinez VG, Hidalgo L, Zapata AG, Vicente A, et al. Wnt5a skews dendritic cell differentiation to an unconventional phenotype with tolerogenic features. J Immunol. (2011) 187:4129-39. doi: 10.4049/jimmunol.1101243

176. Oderup C, LaJevic M, Butcher EC. Canonical and noncanonical Wnt proteins program dendritic cell responses for tolerance. J Immunol. (2013) 190:6126-34. doi: 10.4049/jimmunol.1203002

177. Bergenfelz C, Janols H, Wullt M, Jirstrom K, Bredberg A, Leandersson K. Wnt5a inhibits human monocyte-derived myeloid dendritic cell generation. Scand J Immunol. (2013) 78:194-204. doi: 10.1111/sji.12075

178. Xu WD, Wang J, Yuan TL, Li YH, Yang H, Liu Y, et al. Interactions between canonical Wnt signaling pathway and MAPK pathway regulate differentiation, maturation and function of dendritic cells. Cell Immunol. (2016). 310:170-7. doi: 10.1016/j.cellimm.2016.09.006

179. Luo L, Li Z, Luo G, Zhao Y, Yang J, Chen H. Role of Wnt3a expressed by dendritic cells in the activation of canonical Wnt signaling and generation of memory T cells during primary immune responses. Cell Immunol. (2016). 310:99-107. doi: 10.1016/j.cellimm.2016.08.005

180. Zhou J, Cheng P, Youn JI, Cotter MJ, Gabrilovich DI. Notch and wingless signaling cooperate in regulation of dendritic cell differentiation. Immunity. (2009) 30:845-59. doi: 10.1016/j.immuni.2009.03.021

181. Fu C, Liang X, Cui W, Ober-Blobaum JL, Vazzana J, Shrikant PA, et al. $\beta$ Catenin in dendritic cells exerts opposite functions in cross-priming and maintenance of CD8+ T cells through regulation of IL-10. Proc Natl Acad Sci USA. (2015) 112:2823-8. doi: 10.1073/pnas.1414167112

182. Beckert H, Meyer-Martin H, Buhl R, Taube C, Reuter S. The canonical but not the noncanonical wnt pathway inhibits the development of allergic airway disease. J Immunol. (2018) 201:1855-64. doi: 10.4049/jimmunol.1800554

183. Alves CH, Ober-Blobaum JL, Brouwers-Haspels I, Asmawidjaja PS, Mus AM, Razawy W, et al. Dendritic cell-specific deletion of $\beta$-catenin results in fewer regulatory T-cells without exacerbating autoimmune collagen-induced arthritis. PLoS ONE. (2015). 10:e0142972. doi: 10.1371/journal.pone.0142972

184. Hong Y, Manoharan I, Suryawanshi A, Majumdar T, Angus-Hill ML, Koni $\mathrm{PA}$, et al. $\beta$-catenin promotes regulatory $\mathrm{T}$-cell responses in tumors by inducing vitamin A metabolism in dendritic cells. Cancer Res. (2015) 75:656665. doi: 10.1158/0008-5472.CAN-14-2377

185. Hong Y, Manoharan I, Suryawanshi A, Shanmugam A, Swafford D, Ahmad S, et al. Deletion of LRP5 and LRP6 in dendritic cells enhances antitumor immunity. Oncoimmunology. (2016). 5:e1115941. doi: 10.1080/2162402X.2015.1115941

186. Kerdidani D, Chouvardas P, Arjo AR, Giopanou I, Ntaliarda G, Guo YA, et al. Wnt1 silences chemokine genes in dendritic cells and induces adaptive immune resistance in lung adenocarcinoma. Nat Commun. (2019). 10:1405. doi: 10.1038/s41467-019-09370-z

187. Ichii M, Frank MB, Iozzo RV, Kincade PW. The canonical Wnt pathway shapes niches supportive of hematopoietic stem/progenitor cells. Blood. (2012) 119:1683-92. doi: 10.1182/blood-2011-07-369199

188. Malhotra S, Baba Y, Garrett KP, Staal FJ, Gerstein R, Kincade PW. Contrasting responses of lymphoid progenitors to canonical and noncanonical Wnt signals. J Immunol. (2008) 181:3955-64. doi: 10.4049/jimmunol.181.6.3955

189. Valencia J, Hernandez-Lopez C, Martinez VG, Hidalgo L, Zapata AG, Vicente A, et al. Transient beta-catenin stabilization modifies lineage output from human thymic CD34+CD1a-progenitors. J Leukoc Biol. (2010) 87:40514. doi: $10.1189 / \mathrm{jlb} .0509344$

190. Cohen SB, Smith NL, McDougal C, Pepper M, Shah S, Yap GS, et al. Beta-catenin signaling drives differentiation and proinflammatory function of IRF8-dependent dendritic cells. J Immunol. (2015) 194:210-22. doi: 10.4049/jimmunol.1402453

191. Manoharan I, Hong Y, Suryawanshi A, Angus-Hill ML, Sun Z, Mellor AL, et al. TLR2-dependent activation of beta-catenin pathway in dendritic cells induces regulatory responses and attenuates autoimmune inflammation. $J$ Immunol. (2014) 193:4203-13. doi: 10.4049/jimmunol.1400614
192. Staal FJ, Luis TC, Tiemessen MM. WNT signalling in the immune system: WNT is spreading its wings. Nat Rev Immunol. (2008) 8:581-93. doi: $10.1038 /$ nri2360

193. Famili F, Wiekmeijer AS, Staal FJ. The development of T cells from stem cells in mice and humans. Future Sci OA. (2017). 3:FSO186. doi: 10.4155/fsoa-2016-0095

194. Jeannet G, Boudousquie C, Gardiol N, Kang J, Huelsken J, Held W. Essential role of the Wnt pathway effector Tcf-1 for the establishment of functional CD8 T cell memory. Proc Natl Acad Sci USA. (2010) 107:9777-82. doi: 10.1073/pnas.0914127107

195. Boudousquie C, Danilo M, Pousse L, Jeevan-Raj B, Angelov GS, Chennupati $\mathrm{V}$, et al. Differences in the transduction of canonical Wnt signals demarcate effector and memory CD8 T cells with distinct recall proliferation capacity. $J$ Immunol. (2014) 193:2784-91. doi: 10.4049/jimmunol.1400465

196. Tiemessen MM, Baert MR, Kok L, van Eggermond MC, van den Elsen PJ, et al. T cell factor 1 represses CD8+ effector T cell formation and function. $J$ Immunol. (2014) 193:5480-7. doi: 10.4049/jimmunol.1303417

197. Prlic M, Bevan MJ. Cutting edge: beta-catenin is dispensable for $\mathrm{T}$ cell effector differentiation, memory formation, and recall responses. J Immunol. (2011) 187:1542-6. doi: 10.4049/jimmunol.1100907

198. Zhao DM, Yu S, Zhou X, Haring JS, Held W, Badovinac VP, et al. Constitutive activation of Wnt signaling favors generation of memory CD8 T cells. $J$ Immunol. (2010) 184:1191-9. doi: 10.4049/jimmunol.0901199

199. Chae WJ, Ehrlich AK, Chan PY, Teixeira AM, Henegariu O, Hao $\mathrm{L}$, et al. The Wnt antagonist dickkopf-1 promotes pathological type 2 cell-mediated inflammation. Immunity. (2016) 44:246-58. doi: $10.1016 /$ j.immuni.2016.01.008

200. Farin HF, Jordens I, Mosa MH, Basak O, Korving J, Tauriello DV, et al. Visualization of a short-range Wnt gradient in the intestinal stem-cell niche. Nature. (2016) 530:340-3. doi: 10.1038/nature16937

201. de Roo JJD, Breukel C, Chhatta AR, Linssen MM, Vloemans SA, Salvatori D, et al. Axin2-mTurquoise2: A novel reporter mouse model for the detection of canonical Wnt signalling. Genesis. (2017) 55:e23068. doi: 10.1002/dvg.23068

202. Tao L, Zhang J, Meraner P, Tovaglieri A, Wu X, Gerhard R, et al. Frizzled proteins are colonic epithelial receptors for C. difficile toxin B. Nature. (2016) 538:350-5. doi: 10.1038/nature19799

203. Chen P, Tao L, Wang T, Zhang J, He A, Lam KH, et al. Structural basis for recognition of frizzled proteins by Clostridium difficile toxin B. Science. (2018) 360:664-9. doi: 10.1126/science.aar1999

204. Hayward SD, Liu J, Fujimuro M. Notch and Wnt signaling: mimicry and manipulation by gamma herpesviruses. Sci STKE. (2006). 2006:re4. doi: 10.1126/stke.3352006re4

205. Houschyar KS, Chelliah MP, Rein S, Maan ZN, Weissenberg K, Duscher D, et al. Role of Wnt signaling during inflammation and sepsis: a review of the literature. Int J Artif Organs. (2018) 41:247-53. doi: $10.1177 / 0391398818762357$

206. Takahashi-Yanaga F, Kahn M. Targeting Wnt signaling: can we safely eradicate cancer stem cells? Clin Cancer Res. (2010) 16:3153-62. doi: 10.1158/1078-0432.CCR-09-2943

207. Polakis P. Drugging Wnt signalling in cancer. EMBO J. (2012) 31:2737-46. doi: 10.1038/emboj.2012.126

208. Baron R, Gori F. Targeting WNT signaling in the treatment of osteoporosis. Curr Opin Pharmacol. (2018) 40:134-41. doi: 10.1016/j.coph.2018. 04.011

209. Madan B, Virshup DM. Targeting Wnts at the source-new mechanisms, new biomarkers, new drugs. Mol Cancer Ther. (2015) 14:1087-94. doi: 10.1158/1535-7163.MCT-14-1038

Conflict of Interest: The authors declare that the research was conducted in the absence of any commercial or financial relationships that could be construed as a potential conflict of interest.

Copyright $\odot 2019$ Ljungberg, Kling, Tran and Blumenthal. This is an open-access article distributed under the terms of the Creative Commons Attribution License (CC $B Y)$. The use, distribution or reproduction in other forums is permitted, provided the original author(s) and the copyright owner(s) are credited and that the original publication in this journal is cited, in accordance with accepted academic practice. No use, distribution or reproduction is permitted which does not comply with these terms. 